\title{
THE $5^{\text {TH }}$ INTERNATIONAL FOOd OPERATIONS \& PROCESSING SIMULATION WORKSHOP
}

SEPTEMBER 18-20, 2019

LISBON, PORTUGAL

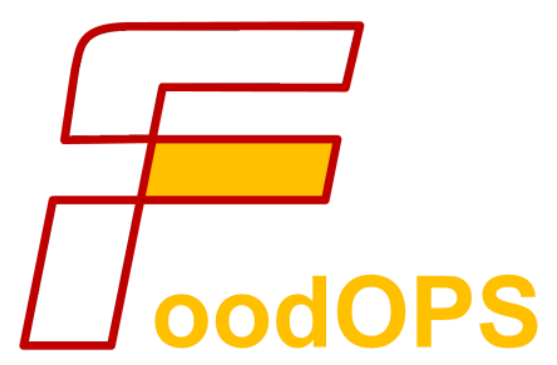

\author{
EDITED BY \\ AgOSTINO G. BRUZZONE \\ FRANCESCO LONGO \\ MIQUEL ANGEL PIERA \\ GIUSEPPE VIGNALI
}

Printed in Rende (CS), Italy, September 2019

ISBN 978-88-85741-40-9 (Paperback)

ISBN 978-88-85741-39-3 (PDF) 


\section{(C) 2019 DIME UniverSità di Genova, DIMEG University OF CaLABRIA}

RESPONSIBILITY FOR THE ACCURACY OF ALL STATEMENTS IN EACH PAPER RESTS SOLELY WITH THE AUTHOR(S). STATEMENTS ARE NOT NECESSARILY REPRESENTATIVE OF NOR ENDORSED BY THE DIME, UNIVERSITY OF GENOA OR DIMEG UNIVERSITY OF CALABRIA. PERMISSION IS GRANTED TO PHOTOCOPY PORTIONS OF THE PUBLICATION FOR PERSONAL USE AND FOR THE USE OF STUDENTS PROVIDING CREDIT IS GIVEN TO THE CONFERENCES AND PUBLICATION. PERMISSION DOES NOT EXTEND TO OTHER TYPES OF REPRODUCTION NOR TO COPYING FOR INCORPORATION INTO COMMERCIAL ADVERTISING NOR FOR ANY OTHER PROFIT - MAKING PURPOSE. OTHER PUBLICATIONS ARE ENCOURAGED TO INCLUDE 300 TO 500 WORD ABSTRACTS OR EXCERPTS FROM ANY PAPER CONTAINED IN THIS BOOK, PROVIDED CREDITS ARE GIVEN TO THE AUTHOR(S) AND THE CONFERENCE.

For permission to publish a COMPLete paper Write to: DIME University of Genoa, Prof. Agostino G. Bruzzone, via Opera Pia 15, 16145 Genova, Italy or to Dimeg University of Calabria, Prof. Francesco LONGO, VIA P.BUCCI 45C, 87036 RENDE, ITALY. AdDITIONAL COPIES OF THE PROCEEDINGS OF THE EMSS ARE AVAILABLE from dime University of Genoa, Prof. Agostino G. Bruzzone, via Opera Pia 15, 16145 Genova, Italy or from Dimeg University of Calabria, Prof. Francesco longo, Via P. Bucci 45C, 87036 Rende, Italy.

\section{ISBN 978-88-85741-40-9 (Paperback) ISBN 978-88-85741-39-3 (PDF)}




\section{The International Food Operations \& Processing SIMULATION WORKSHOP, FOODOPS 2019 \\ SEPTEMBER 18 - 20, 2019 \\ LISBON, PORTUGAL}

\section{ORganized BY}

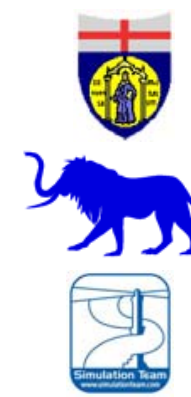

In

理

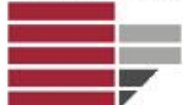

MSC

Les

으

mtaE?

10

\section{UAB}
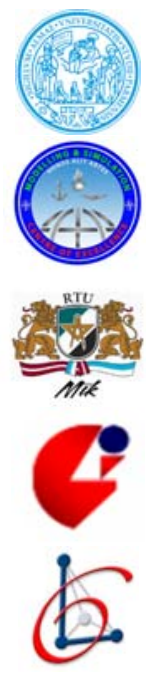

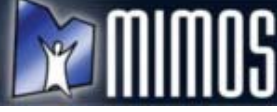

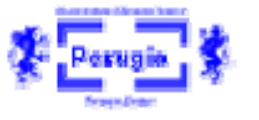

DIME - UNIVERSITY OF GENOA

LIOPHANT SIMULATION

Simulation TeAm

IMCS - INTERnational MediterRanean \& Latin American CounCiL of

SIMULATION

DIMEG, UNIVERSITY OF CALABRIA

MSC-LES, MOdeling \& Simulation Center, LABORATORY OF ENTERPRISE SOLUTIONS

Hungarian Academy Of Sciences Centre For Energy Research

AUTONOMOUS UNIVERSITY OF BARCELONA

UNIVERSITY OF PARMA

Modeling and Simulation Center of ExCellence (MSCOE)

LatVian Simulation Center - Riga Technical University

LOGISIM

LSIS - LABORATOIRE DES SCIENCES DE L'INFORMATION ET DES SYSTEMES

MIMOS - Movimento Italiano Modellazione e SimUlaZIONe

Mitim Perugia Center - University of Perugia 


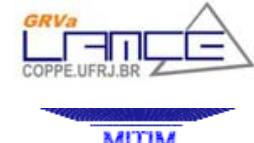

MITIM Simulation Team Genoa Center

MiSNet

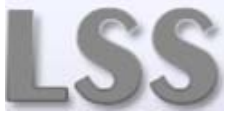

$\underline{\underline{\underline{S}} I \overline{\bar{S}} A}$

FCER

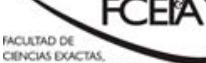

ULL I luikeridid

CIFASIS

CONICET

IITSTICC

(nom

窟

université BORDEAUX

University of Cyprus

DBSS

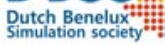

市<smiles>C1#C[AlH]1</smiles>

UNR|UPCAM

Brasilian Simulation Center, LAMCE-COPPE-UFRJ

MITIM - MCLEOd INSTITUTE OF TECHNOLOGY AND INTEROPERABLE MODELING AND Simulation - Genoa Center

M\&SNet - MCLeOd Modeling ANd SimUlation NetWORK

LatVian SimUlation SOCIETY

Ecole Superieure d'Ingenierie en SCIenCes AppliqueES

FACUltad de Ciencias EXactas. IngEgneria y Agrimensura

UNIVERSITY OF LA LAGUNA

CIFASIS: CONICET-UNR-UPCAM

INSTICC - INSTITUTE FOR SYSTEMS AND TECHNOLOGIES OF INFORMATION, CONTROL AND COMMUNICATION

National Russian Simulation Society

CEA - IFAC

UNIVERSITY OF BORDEAUX

UNIVERSITY OF CYPRUS

DutCh Benelux Simulation SOCIETy

UNINEAERSMTDOAMNMIIIIEIO

I3M 2019 INDUSTRIAL SPONSORS

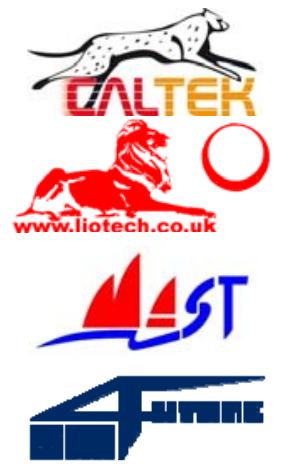

CAL-TEK SRL

LIOTECH LTD

MAST SRL 


\section{I3M 2019 MEDIA PARTNeRS}

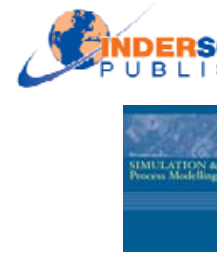

INDERSCIENCE PUBLISHERS - INTERNATIONAL J OURNAL OF SIMULATION AND PROCESS MODELING

INDERSCIENCE PUBLISHERS - INTERNATIONAL J OURNAL OF SERVICE AND COMPUTING ORIENTED MANUfACTURING

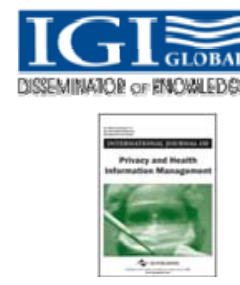

IGI GLOBAL - INTERNATIONAL J OURNAL OF PRIVACY AND HEALTH INFORMATION MANAGEMENT (IJ PHIM)

\section{$\nabla$}

Halldale Group

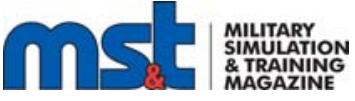

Halldale Media Group: The Military Simulation and Training Magazine

MedicalTraining

Halldale Media Group: The J ournal for Healthcare Education, SimUlation AND TRAINING

(SAGE

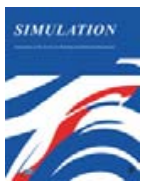

SAGE

SIMULATION TRANSACTION OF SCS

DE GRUYTER

INTERNATIONAL J OURNAL OF FOOD ENGINEERING

sustainability MDPI - SUSTAINABILITY

\section{धपhomerci}

EUROMERCI: THE ITALIAN MONTHLY LOGISTICS J OURNAL 


\section{EDITORS}

Agostino BRUZZONE

MITIM-DIME, UNIVERSITY OF GENOA, ITALY

agostino@itim.unige.it

Francesco Longo

DIMEG, UNIVERSITY OF CALABRIA, ITALY

f.longo@unical.it

Miquel Angel Piera

AUTONOMOUS UNIVERSITY OF BARCELONA, SPAIN

MiQuelANGEL.PIERA@UAB.CAT

\section{GiUseppe Vignali}

UNIVERSITY OF PARMA, ITALY

giusppe.vignali@unipr.it 


\title{
The INTERNATIONAL MULTIDISCIPLINARY MODELING AND SIMULATION MULTICONFERENCE, I3M 2019
}

\author{
General Co-Chairs \\ Agostino BruzZONe, MITIM DIME, UNIVERSITY OF GENOA, ITALY \\ Miquel Angel Piera, Autonomous University of BarCelona, Spain

\section{Program Co-Chairs} \\ Francesco Longo, DIMEG, UNIVERSITY of CaLABRIA, Italy \\ YURY MERKURYEV, RIGA TECHNICAL UNIVERSITY, LATVIA
}

\section{The International Food Operations \& Processing Simulation WORKSHOP, FOODOPS 2019}

\author{
General Chair \\ GIUSEPPE Vignali, UnIVERSITY OF PARMA ITALY \\ Program Chair \\ FRANCESCO LONGO, DIMEG, UNIVERSITY OF CALABRIA, ITALY
}


FoodOPS 2019 International Program

\section{CommitTee}

ELEONORA BOTTANI, UNIVERSITY OF PARMA, ITALY AgOSTINO BRUZZONE, DIME, UNIVERSITY OF GENOA, ITALY

GERSON GOMES CUNHA, COPPE UFRJ , BRAZL

Michel HAVET, GEPEA RESEARCH UNIT, FRANCE

FRANCESCO LONGO, MSC-LES, UNIVERSITY OF CALABRIA, ITALY

FRANCESCO MARRA, UNIVERSITY OF SALERNO, ITALY

MARINA MASSEI, LIOPHANT SIMULATION, ITALY

Ruben MERCADE PRIETO, SOOCHOW UNIVERSITY, CHINA

YURI MERKURYEV, RIGA TECHNICAL UNIVERSITY, LATVIA

ROBERTO MONTANARI, UNIVERSITY OF PARMA, ITALY

LetizIa NicolettI, CaL-TEK SRL, ITALY

ANTONIO PADOVANO, UNIVERSITY OF CALABRIA, ITALY

Miquel ANGel Piera, UNiversity of BARCELONA, SPAIN

OLIVIER ROUAUd, GEPEA RESEARCH UNIT, FRANCE

SteFANO SAETTA, UNIVERSITY OF PERUGIA, ITALY

FEDERICO SOLARI, UNIVERSITY OF PARMA, ITALY

TOMAS SKOGLUND, TETRAPAK, SWEDEN

J ACK VANDER VORST, ORL GROUP - WAGENINGEN UNIVERSITEIT, NL

GIUSEPPE VIGNALI, UNIVERSITY OF PARMA, ITALY

MUSTAFA TAHSIN YILMAZ, YILDIZ TEKNIK ÜNIVERSITESI, TURKEY

\section{TRACKS AND WORKSHOP CHAIRS}

LIQUID FOOD PROCESSING

Chair: MARCo Better, OptTek Systems (US)

MODELLING AND SIMULATION OF FOOD PROCESSING

Chair: Michel HAVET, GEPEA RESEARCH UNIT, FranCE

MOdELLING AND SIMULATION OF FOOD PROPERTIES

ChaIR: MUSTAFA TAHSIN YILMAZ, YILDIZ TEKNIK ÜNIVERSITESI,

TURKEY

SUSTAINABILITY OF FOOD PROCESSES

Chair: GiUseppe Vignali, UniVersity of PARMA, ITALY

MODELLING AND SIMULATION OF FOOD FOULING AND CLEANING

TECHNIQUES

Chair: Ruben Mercade Prieto, Soochow University, China

MODELING OF TRANSPORT PHENOMENA IN FOOD PROCESSES

ASSISTED BY MICROWAVES AND RADIO-FREQUENCIES

Chair: Francesco MARRA, University of SAlERno, ItALY 


\section{Chairs' Message}

\section{WELCOME TO FOODOPS 2019!}

We are delighted to welcome our international and national presenters and delegates to The 5th International Food Operations and Processing Simulation Workshop (FOODOPS).

The workshop will offer plenty of networking opportunities with leading scientists and researchers, friends and colleagues. We are very proud and excited to be hosting FOODOPS in Lisbon one of the most beautiful European capitals that offers a variety of cultural activities to make even more memorable your attendance to FOODOPS.

And as always, we endeavor to provide you with a good scientific program including meaningful contributions in the area of innovative technologies for Food Logistics, Life-Cycle Assessment Methodologies and Modeling approaches in Food Industry.

But FoodOPS mean more. FoodOPS indeed provides the opportunity to form productive collaborations and lasting friendships with like-minded academics around the globe. Beside FoodOPS is a motivational experience exposing our young colleagues to the latest innovations in our fields as a springboard to their own research and discoveries.

With this in mind, we would like to express our sincere thanks to the program committee and to the local organization committee for carefully reviewing all paper submissions and for putting together this interesting program.

We wish you an amazing and inspiring experience in Lisbon!

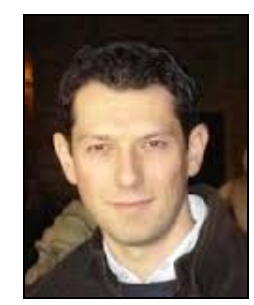

Giuseppe Vignali

University of Parma Italy

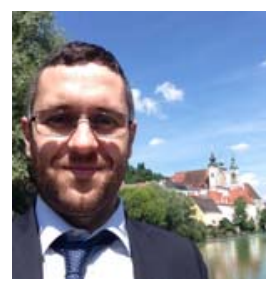

Francesco Longo

University of Calabria Italy 


\section{ACKNOWLEDGEMENTS}

The FoodOPS 2019 International Program Committee (IPC) has selected the papers for the Conference among many submissions; therefore, based on this effort, a very successful event is expected. The FoodOPS 2019 IPC would like to thank all the authors as well as the reviewers for their invaluable work.

A special thank goes to all the organizations, institutions and societies that have supported and technically sponsored the event.

\section{I3M 2019 INTERNAL STAFF}

AgOSTINO G. BRUZZONE, DIME, UNIVERSITY OF GENOA, ITALY ALESSANDRO CHIURCO, CAL-TEK SRL, ITALY J ESSICA FRANGELLA, DIMEG, UNIVERSITY OF CALABRIA, ITALY CATERINA FUSTO, DIMEG, UNIVERSITY OF CALABRIA, ITALY LUCIA GAZZANEO, DIMEG, UNIVERSITY OF CALABRIA, ITALY FRANCESCO LONGO, DIMEG, UNIVERSITY OF CALABRIA, ITALY MARINA MASSEI, DIME, UNIVERSITY OF GENOA, ITALY

LETIZIA NICOLETTI, CAL-TEK SRL, ITALY

ANTONIO PADOVANO, DIMEG, UNIVERSITY OF CALABRIA, ITALY

CATALDO RUSSO, CAL-TEK SRL, ITALY

KIRILL SINELSHCHIKOV, SIMULATION TEAM, ITALY

MARCO Vetrano, CAL-TEK SRL, ITALY 

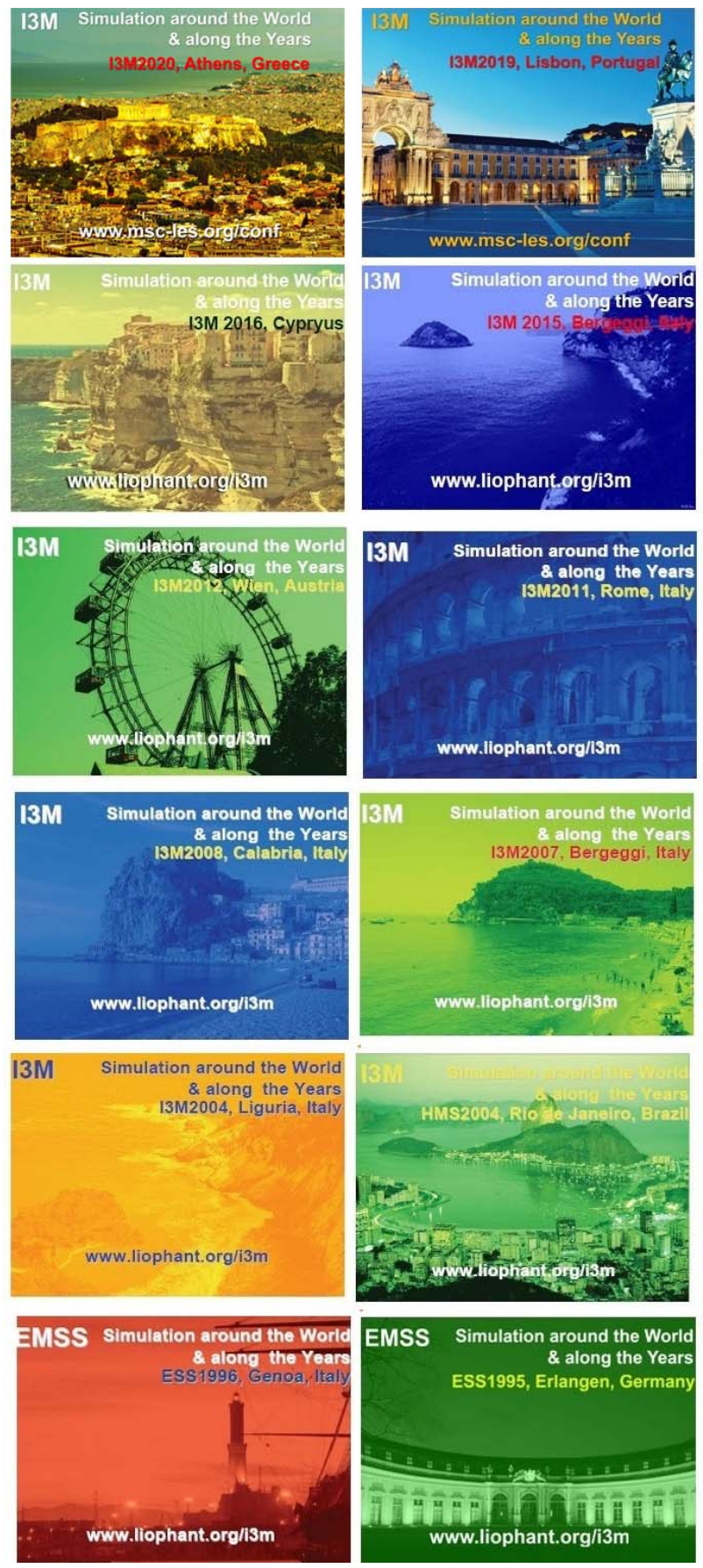
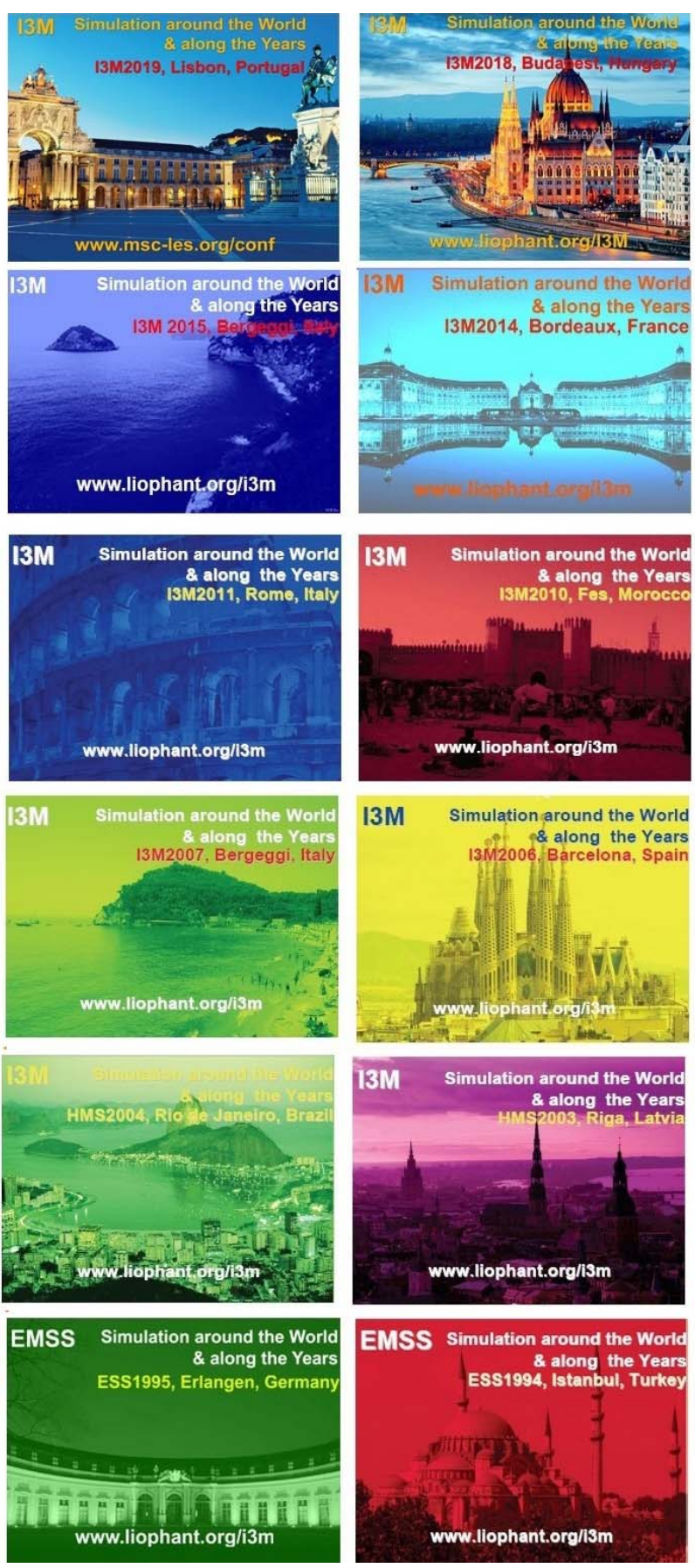
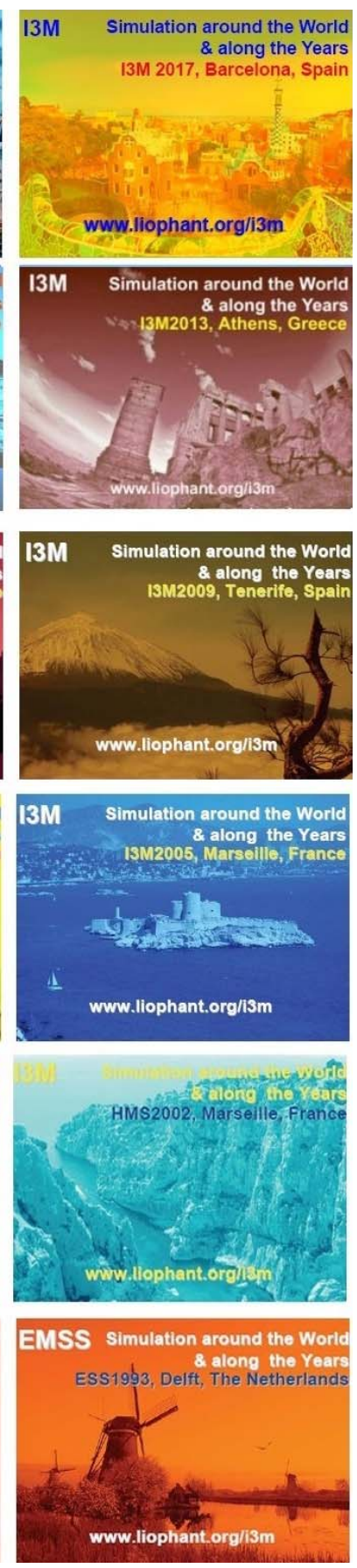


\section{Index}

Impact of RFID-TTI technologies on the efficiency of perishable products logistics

E. M. Cepolina, E. Cangialosi, I. Giusti, D. Aquaro, G. Caroti, A. Piemonte

A testing procedure of a digital application for safety improvement in a beverage plant

G. Vignali, N. Guareschi, L.Tebaldi, F. Longo, L. Di Donato, A. Ferraro, E. Bottani

Modelling the growth kinetic of spoilage microorganisms in a packaged cow's ricotta processed with high pressure

R. Stefanini, G. Vignali, F. Coloretti

Life cycle assessment of organic Parmesan Cheese considering the whole dairy supply chain

G. Borghesi, G. Vignali 


\title{
IMPACT OF RFID-TTI TECHNOLOGIES ON THE EFFICIENCY OF PERISHABLE PRODUCTS LOGISTICS
}

\author{
Elvezia Maria Cepolina ${ }^{(a)}$, Edoardo Cangialosi ${ }^{(b)}$, Ilaria Giusti ${ }^{(c)}$, \\ Donato Aquaro $^{(\mathrm{d})}$, Gabriella Caroti ${ }^{(\mathrm{e})}$, Andrea Piemonte ${ }^{(\mathrm{f})}$ \\ (a) DISPO - University of Genova \\ (b), (c), (d), (e), (f) DICI - University of Pisa \\ ${ }^{(a)} \underline{\text { elvezia.maria.cepolina@unige.it, }}{ }^{\text {(b) }}$ edoardo.cangialosi@dici.unipi.it, ${ }^{(c)}$ ilaria.giusti@ for.unipi.it, \\ ${ }^{(d)}$ donato.aquaro@unipi.it, ${ }^{(e)}$ gabriella.caroti@unipi.it, ${ }^{(\mathrm{f})}$ andrea.piemonte@ unipi.it
}

\begin{abstract}
The paper concerns the logistics activities related to perishable products. Perishable products are delivered from the production site to a warehouse by refrigerated truck. Perishable products are accepted or not at the warehouse entrance, according to their detected quality levels; if accepted, they are stored in the warehouse in suitable environmental conditions. Finally, they are delivered by refrigerated truck to the destination. Human errors affect these activities. Perishable products have to be delivered in a suitable quality level to the destination. Because of human errors, sometime products arrive in an unsuitable quality level and therefore, there is a loss for the company.

RFID technologies, integrated with time temperature indicators (TTI), allow a prompt detection of abnormal quality loss and the prompt actuation of mitigation actions.

In order to evaluate the benefits of different RFID-TTI implementation set-ups, the study defines a methodology that measures the risk of monetary losses. The method is applied to a case study and the results are presented.
\end{abstract}

Keywords: perishable products, RFID-TTI implementation set-ups, logistics, transport.

\section{INTRODUCTION}

\subsection{Perishable products}

Most perishable products are temperature sensitive and their quality level is therefore a function of product characteristics, conditions under which the product is maintained, and time (Sahin et al. 2007).

Sloof et al. (1996) introduced four mathematical descriptions to express the decrease in value of perishable products in a fixed environment. These four models are listed below:

- Zero order reactions having linear kinetics.

- Michaelis Menten kinetics.

- First order reactions having exponential kinetics.

- Autocatalytic reactions with logistic kinetics (Tijskens and Polderdijk, 1996).
A relationship between time and quality of perishable products can be built based on these models (Wang et al. 2010). For the same value of the initial quality and the same value of the quality limit, Figure 1 gives a summary of the change of quality attributes based on these four kinetic mechanisms. The

functions of the linear kinetics model and the Michaelis Menten model are nearly the same in the initial period, so, most part of the two curves are overlapping in the figure.

In the figure, KQ indicates the "keeping quality": the time that elapses between the production and the instant in which the quality deteriorates beyond an acceptance level.

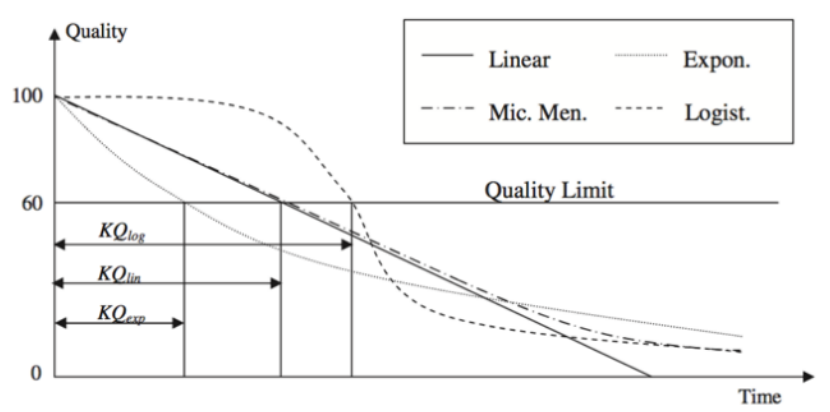

Figure 1: Decrease in quality for four types of mechanisms (Tijskens and Evelo, 1994)

\subsection{RFID-TTI technology}

Advanced product identification and sensory technologies, such as radio frequency identification technology (RFID) and time temperature indicator (TTI), enable to record transit times and time-temperature data that determine the actual perishable product quality. Therefore, these technologies allow a prompt detection of abnormal quality loss and therefore a prompt actuation of mitigation actions is possible.

As it concerns the reading (of the RFID-TTI sensor tag) and the transmission (to the information system), two possibilities can be considered: the reader and middleware read and transmit (1) only the latest sensor 
data or (2) all sensor data in a tag user memory. The first approach can be applied to systems that can send sensor data to information systems anywhere and in real-time through wireless communication devices. The second approach can be used when wireless communication is not available (Kang et al., 2012). According to these reading/transmission options and according to the locations where the reading/transmission takes place, different RFID-TTI implementations scenarios can be defined.

\section{SYSTEM MODEL DEVELOPMENT}

\subsection{The logistic processes}

The logistic processes taken into account are the ones that take place from the instant in which perishable products arrive at the warehouse to the instant they arrive at the destination. Goods arrive at the warehouse usually by refrigerated truck. Perishable freight units are managed as bulk goods in the warehouse. In the proposed study, each freight unit is subject to the following logistic activities (Figure 2):

- Check-in at the warehouse entrance: according to documentation check and visual checks on package status, goods are accepted or rejected at the receiving dock. In this phase, conservation instructions, shipping and priorities information are acquired. Freight units are tagged with labels reporting this information and then moved inside the warehouse.

- Refrigerating room: once the check-in procedure is concluded, freight units are stored inside the correct refrigerating room, based on conservation instructions.

- Truck consolidation: once the truck is available at the leaving dock, freight units are moved from the refrigerating room to the loading dock. Here, the truck is consolidated for last mile freight distribution (Cepolina, 2016; Cepolina and Farina, 2015). According to the data from the case study, the truck capacity is equal to 13 units.

- Freight transport to destination by refrigerating truck. From here, freight units will be delivered to urban areas possibly by multi modal systems (Molfino et al. 2015).

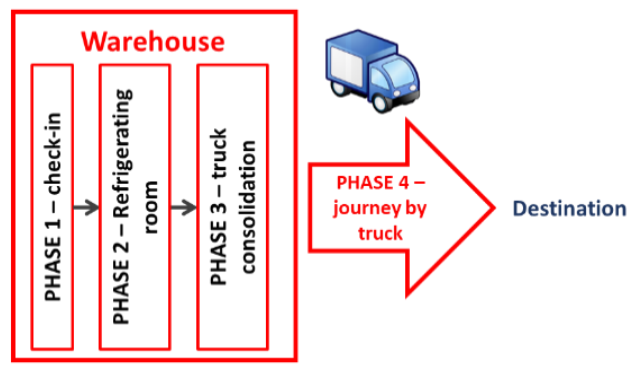

Figure 2: The simulated logistic processes.
Referring to Figure 3, in the paper Initial Quality Limit (IQL) is meant as the minimum acceptable quality level of the product at the check in (phase 1): the product should arrive at the warehouse entrance at a quality level $>$ IQL. Final Quality Limit (FQL) is meant as the minimum acceptable product quality level at the destination: the perishable product should be delivered at the destination at a quality level > FQL. KQ is meant as the length of time from the product acceptance at the warehouse entrance to the time in which the quality deteriorates beyond FQL. Therefore, KQ is the maximum time interval at disposal for transferring freight from the warehouse to the destination in specific ideal conditions.

\subsection{Human preservation errors}

In the four phases previously described, human errors can occur.

Only errors those consequences could be reduced by RFID-TTI implementations will be considered. Thus, the human error typologies taken into account are:

- Previous preservation error (type pp): products arrive at the warehouse entrance with a quality level $<$ IQL because of errors previously occurred.

- Conservation error (type c): units are put in the refrigerating room with delay.

- Setting error (type s): units are placed in the wrong refrigerating room (i.e. wrong temperature set-up)

Errors of type pp definitely compromise the products that in fact cannot be anymore delivered to the destination in a quality level $>$ FQL.

The last two error types are preservation errors that occur in the warehouse and that cause an abnormal freight unit quality loss, specifically:

- Errors of type c lead to a significant quality degradation

- Errors of type s lead to a slight quality degradation In both cases, products can be delivered, or not, to the destination in a quality level >FQL. When actual conditions (indicated in the following with the symbol*) deviate from specified ideal conditions because of conservation/setting error occurrence, the quality decrease will be faster and the linear function describing the kinetic mechanisms will be steeper than that referring to ideal conditions; FQL will be sooner reached and therefore, $\mathrm{KQ}^{*}$ will be shorter than $\mathrm{KQ}$ (Figure 4) and $\mathrm{KQ}^{* *<} \mathrm{KQ}^{*}<\mathrm{KQ}$ (Figure 5 and 6).

The quality loss entity depends not only on the error type but also on the amplitude of the interval of time that elapses between the moment in which an error occurs and the instant in which mitigation actions are implemented.

Without any RFID-TTI implementation, the quality level of each freight unit is monitored through temperature sensors placed by the producer within the pack and checked only at destination, once the package is opened. 
Therefore, only at destination the temperature sensors are read and, if an error occurred, there is no way to mitigate it.

The introduction of RFID-TTI technology with different implementation set-ups impacts on: preservation error detection, actuation time of possible mitigation actions and thus, error consequence entity.

\subsection{Scenario definition}

Two scenarios are taken into account:

* Scenario NO RFID. It represents the current situation without any RFID-TTI implementation. Human errors of types $p p), c$ ) and $s$ ) can take place and are detected at destination. Therefore, no mitigation actions are possible. * Scenario D - RFID-TTI implementation. The scenario refers to a RFID-TTI set-up where: RFID-TTI tags are applied by the producer to each freight unit and fixed RFID readers (portals) are located: at the warehouse entrance (reading point E); at the entrance (reading point I) and at the exit (reading point $\mathrm{U}$ ) of the refrigerating room. Errors are detected only when the RFID reading happens: reading point $\mathrm{E}$ allows to detect type $p p$ errors; reading point I allows to detect type $c$ errors; reading point $\mathrm{U}$ allows to detect type s errors.

\subsection{Mitigation actions}

Once an error has been detected, the following mitigation actions are possible:

1. Product rejection - in case of detection of a type $p p$ error, the product is rejected: this mitigation action is always successful.

2. Express delivery - in case of detection of a type $c$ error: a truck with the compromised unit leaves the warehouse as soon as possible without waiting for other units. Therefore, the load factor (given by the rate between the number of units on the truck and the truck capacity) is lower than 1 and an additional truck will be required for delivering the remaining units that have been left in the warehouse for time saving. This mitigation action can be successful or not.

3. Accelerated delivery - in case of detection of a type $s$ error: the truck reaches the destination in the minimum time, thanks to an increase in the commercial speed (for instance trough a reduction of the stop lengths, increase in the actual speed, rerouting). In this case the truck leaves the warehouse only when it has been consolidated with all the units, therefore, its load factor is equal to 1 and no additional trucks are required. This mitigation action can be successful or not, as described in section 2.5.

4. Travel cancellation - in case of type c error or type $s$ error occurrences. If the previous mitigation actions are ineffective, there is no way for the company to deliver the compromised unit to the destination with a suitable quality level. In this case the subsequent transport phases are cancelled and, although the unit is lost, additional and useless travel costs can be saved.

\subsection{Assessment of mitigation action's success}

The following figures show Quality-Space-Time diagrams for a perishable product. The quality level is assumed to decrease linearly with time in specific ideal conditions. Q1 is the initial quality level of the freight unit at the warehouse entrance, while QD is the quality level at destination. FQL is the minimum quality level accepted at destination. $t_{1}$ is the unit entrance time in the warehouse. $t_{2}$ is the unit exit time from the warehouse. $t_{2}-$ $t_{1}$ is the permanence duration of the unit in the warehouse. $t_{D}$ is the time the unit is delivered to the destination. $t_{D}-t_{2}$ is the travel time from the warehouse to the destination. $t_{\mathrm{L}}$ is the time the unit reaches FQL. $t_{\mathrm{L}}-\mathrm{t}_{1}=$ $\mathrm{KQ}$ referred to specific ideal conditions.

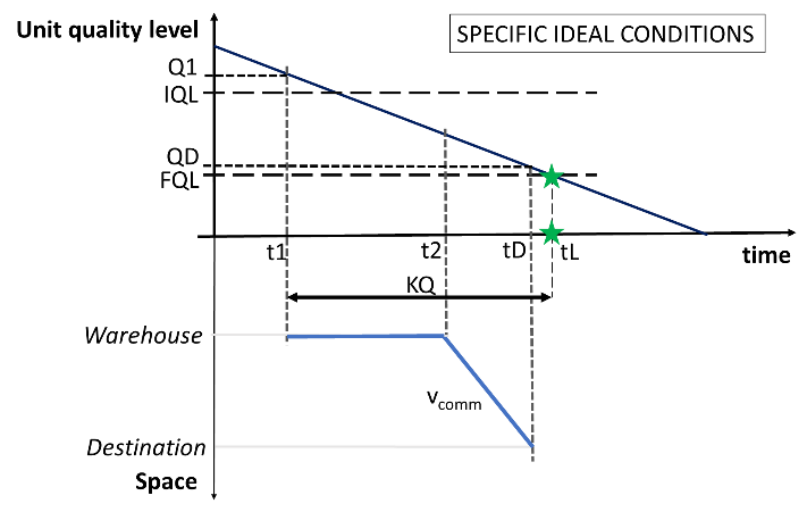

Figure 3: quality degradation with time in specific ideal conditions.

Figure 3 shows that in specific ideal conditions, $\left(t_{D}-t_{1}\right)<$ $\mathrm{KQ}$. $\mathrm{v}_{\text {comm }}$ is the normal truck commercial speed from the warehouse to the destination. The unit arrives at destination with a quality level $>\mathrm{FQL}(\mathrm{QD}>\mathrm{FQL})$.

Figure 4 shows an example of type s error occurrence and the consequent adoption of the accelerated mitigation action. The error produces an increase of the perishable product degradation speed and as a consequence $\mathrm{KQ}^{*}<$ KQ. An accelerated mitigation action has been adopted and the transport from the warehouse to the destination is performed at $\mathrm{V}_{\text {commax }}\left(>\mathrm{V}_{\text {comm }}\right)$, which is the maximum commercial speed. The mitigation action results successful since $\left(t_{D}-t_{1}\right)<K Q *$ and therefore $Q D>F Q L$. 


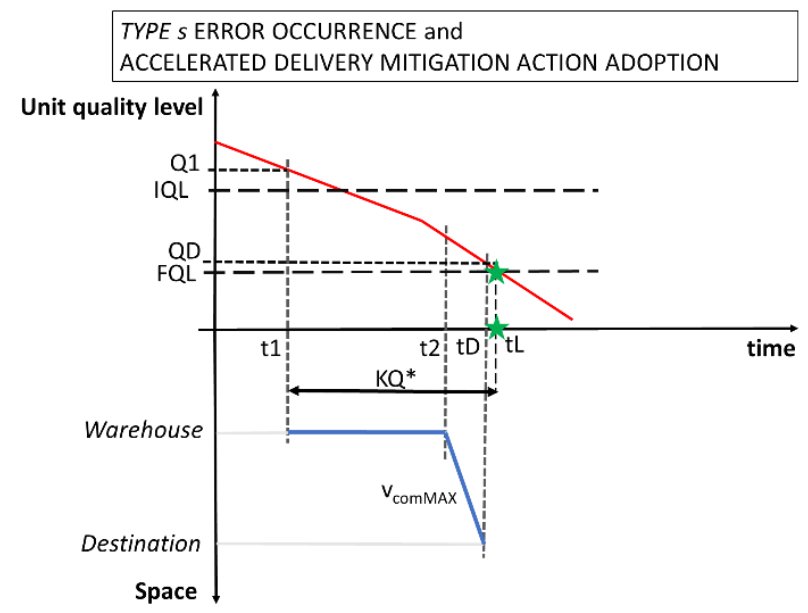

Figure 4: an example of type $s$ error occurrence and the consequent adoption of the "accelerated mitigation action". The mitigation action results successful.

TYPE $C$ ERROR OCCURRENCE and

ACCELERATED DELIVERY MITIGATION ACTION ADOPTION

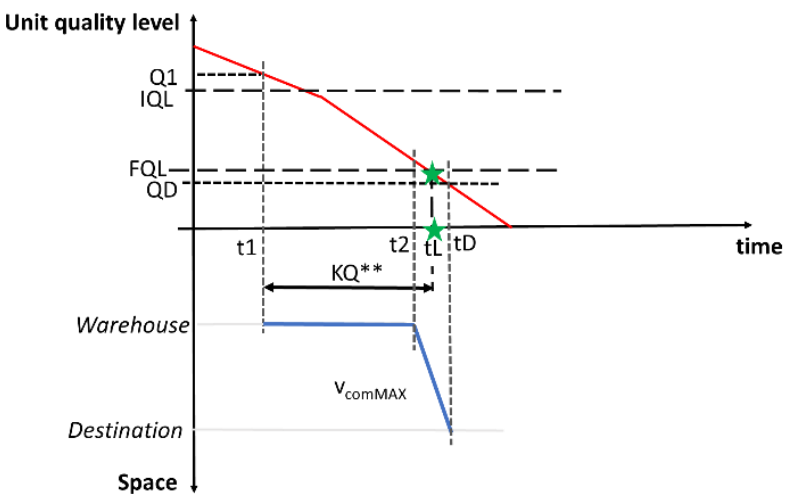

Figure 5: an example of type $c$ error occurrence and adoption of the "accelerated mitigation action". The mitigation action results unsuccessful.

Figure 5 refers to a type $c$ error occurrence and the adoption of the accelerated mitigation action. The error produces a strong increase of the perishable product degradation speed and, as a consequence, $\mathrm{KQ}^{* *}<<\mathrm{KQ}$. An accelerated mitigation action has been adopted and the transport from the warehouse to the destination is performed at $\mathrm{v}_{\text {commax }}\left(>\mathrm{v}_{\text {comm }}\right)$, which is the maximum commercial speed. The mitigation action results unsuccessful since $\left(t_{D}-t_{1}\right)>K Q^{* *}$ and therefore $Q D<$ FQL.

Figure 6 refers to a type $c$ error occurrence and express mitigation action adoption. The error produces a strong increase of the perishable product degradation speed and as a consequence $\mathrm{KQ}^{* *}<<\mathrm{KQ}$. An express mitigation action has been adopted therefore the compromised product stays for a shorter time in the warehouse $\left(t_{2}-t_{1}\right.$ in Figure $6 \ll t_{2}-t_{1}$ in Figure 5): as soon as the error is detected, freight leaves the warehouse. The transport from the warehouse to the destination is performed at $\mathrm{v}_{\text {comm }}$. The mitigation action results successful since $\left(t_{D}-\right.$ $\left.\mathrm{t}_{1}\right)<\mathrm{KQ}^{* *}$ and therefore $\mathrm{QD}>\mathrm{FQL}$.

TYPE $c$ ERROR OCCURRENCE and EXPRESS DELIVERY MITIGATION ACTION ADOPTION

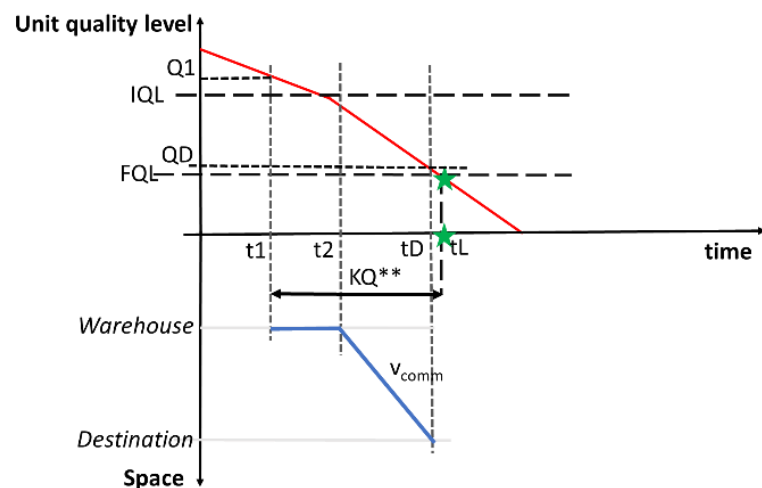

Figure 6: an example of type $c$ error occurrence and adoption of the "express mitigation action". The mitigation action results successful.

\section{METHODOLOGY}

\subsection{Goal and scope definition}

A simulative analysis is aimed at assessing benefits of the previously described scenarios.

For each scenario, benefits are assessed in terms of reduced risk of monetary loss (Cepolina et al. 2018, Cepolina et al. 2019a). A low value of risk means a high-performance scenario.

In a given scenario $S, R^{S}$ is assessed by summing for each damage class, the product between the average of the total damage levels belonging to the class, $\mathrm{A} D_{d c}$, and the occurrence probability, $H_{d c}$, related to the respective class:

$$
R^{S}=\sum_{d c} A D_{d c} * H_{D_{d c}}
$$

The classes of damage are 5: Negligible (if total damage level < 500 euro), Minor (if 501 euro < total damage level < 1000 euro), Moderate (if 1001 euro < total damage level < 3000 euro), Significant (if 3001 euro < total damage level $<5000$ euro), Severe (if 5001 euro < total damage level).

The steps for calculating $A D_{d c}$ are:

- assessing the damage level $d_{i}$ experienced by each freight unit $i$ in the scenario $\mathrm{S}$, in the reference time period. This is done performing a run $\left(n^{\text {th }}\right.$ run) of a discrete event simulation

- in the $n^{\text {th }}$ run, assessing the total damage level as: $D_{n}=\sum_{i=1}^{F U N} d_{i}$, extended to the overall number $F U N$ of freight units handled in the reference time period. The resulting total 
damage level $D_{n}$ is reported to the related class $D_{d c}$.

- For each class $D_{d c}: A D_{d c}=\frac{\sum_{n d c} D_{n d c}}{N_{D_{d c}}}$ where $D_{n d c}$ are the values $D_{n}$ that fall within the $D_{d c}$ class and $N_{D_{d c}}$ is the total number of $D_{n d c}$

- $H_{d c}$ is the probability that, in the reference time period, the scenario is affected by the total damage level that belongs to class $d c$. This probability is assessed by Monte Carlo technique according to the procedure illustrated in Cepolina et al. (2019b). The following likelihood classes are considered: very unlikely $(0-0,2)$, unlikely $(0,21-0,4)$, possible $(0,41-0,6)$, likely $(0,61-0,8)$ and very likely $(0,81-1)$.

\subsection{Assessment of the damage level $d_{i}$ - Discrete event simulation}

During the $n^{\text {th }}$ run of the discrete event simulation, the freight units are processed through the four logistic phases in Figure 2, human errors are generated, and eventual mitigation actions are applied.

For each freight unit $i$, damage level $d_{i}$ is assessed by:

$d_{i}=V_{i} * E_{i}+K_{1} *$ travel cost ${ }_{i}^{\text {extra }}+K_{2} *$

travel cost $t_{\text {truck }}-K_{3} *$ travel cost $t_{i}^{\text {normal speed }}$

where:

Exposition $E_{i}$ is the monetary value of freight unit $i$ that includes the cost of moving a unit from the warehouse to the destination by a full load refrigerated truck (load factor $=1$ ) with the normal commercial speed.

Vulnerability, $V_{i}$ is a Boolean variable: $V_{i}=1$ when: -) a type pp error occurs but it is not detected at the check in and therefore product rejection mitigation action is not adopted; -) a type $s$ error or a type $c$ error occurs but it is not detected; -) a type $s$ error or a type $c$ error occurs and it is detected in the warehouse but the adopted express delivery or accelerated delivery mitigation actions do not result effective (QD $<\mathrm{FQL}$ ). In all the other cases $V_{i}=0$. In case $V_{i}=1$, the damage is equal to the costs related to the complete compensation of compromised units to the customer. If the unit quality level, detected in the warehouse, results < FQL, the damage value can be reduced by canceling the unnecessary transport of the compromised unit.

travel cost ${ }_{i}^{\text {normal speed }}$ is the cost of moving a unit from the warehouse to the destination by a full load refrigerated truck with the normal commercial speed.

travel cost $t^{\text {extra }}$ is the difference between:

- the cost of moving a unit from the warehouse to the destination by a full load refrigerated truck with the maximum commercial speed (through increased speed, rerouting and stop length reduction).
- $\quad$ travel cost $t_{i}^{\text {normal speed }}$

travel cost $t_{\text {truck }}$ is the cost of an additional refrigerated truck for moving freight from the warehouse to the destination

$K_{l}$ is a Boolean variable: $K_{l}=1$ when an accelerated delivery mitigation action takes place; $K_{l}=0$ otherwise.

$K_{2}$ is a Boolean variable: $K_{2}=1$ when an express delivery mitigation action takes place and the additional truck travels with load factors $<1 ; K_{2}=0$ otherwise.

$K_{3}$ is a variable: $K_{3}=1$ when a travel cancellation mitigation action takes place; $K_{3}=0$ otherwise.

\section{DISCRETE EVENT SIMULATOR \\ 4.1. Simulation data input}

The simulation model has been implemented in Anylogic, a discrete event analysis has been adopted.

The system is defined by:

- $\quad$ the reference time period: a typical 8 hours working day has been considered.

- the freight demand, specified in terms of:

- number of freight units that arrive at the warehouse within the reference time period: 364

- freight arrival rate: it has been assumed uniform and arrivals have been assumed deterministic.

- freight unit economic value: referring to perishable units, we assumed each freight unit has a value of 3349 euro. The value is obtained considering: 19 SDRs/kg (Special Drawing Rights) where 1 SDRs $=1.23$ euro, unit's weight equal to140 $\mathrm{kg}$, average transport cost equal to 77 euro for an average distance of $400 \mathrm{~km}$.

- four process phases as described in Figure 2. Process times are assumed deterministic and are shown in Table 1.

- human preservation error probabilities: we assumed a Bernoulli distribution for human errors with mean values equal to 0.001430 for type $c$ conservation errors, 0.002143 for type $s$ setting errors and 0.000357 for type pp previous preservation errors.

Table 1: Process times.

\begin{tabular}{|l|l|l|}
\hline & & Process times \\
\hline Phase 1 check in & Freight unit & $17,5 \mathrm{~s}$ \\
\hline $\begin{array}{l}\text { Phase 2 refrigerating } \\
\text { room }\end{array}$ & Freight unit & $25200 \mathrm{~s}(7 \mathrm{~h})$ \\
\hline $\begin{array}{l}\text { Phase } 3 \text { truck } \\
\text { consolidation }\end{array}$ & truck & $900 \mathrm{~s}$ \\
\hline Phase 4 journey by truck & truck & $28800 \mathrm{~s}(8 \mathrm{~h})$ \\
\hline
\end{tabular}


- mitigation action costs:

- Product rejection: the unit is rejected without any other transport cost and any other administrative and legal cost requested in case of dispute

- Express delivery, the cost (travel cost $t_{\text {truck }}$ ) is related to the additional requested truck. Its total travel cost is assumed equal to 900 euro that is the total cost of a $400 \mathrm{~km}$ journey performed by a van with gross vehicle weight $<3$,5t. It has been assessed with the data provided by the Italian Observatory on road freight transport activities (http://www.mit.gov.it/mit/mop_all.php?p_i $\underline{\mathrm{d}=10640)}$ ) and assuming that variable costs constitute about $44 \%$ of the total travel cost (Jacyna and Wasiak, 2015).

- Accelerated delivery, the cost (travel cost $t_{i}^{\text {extra }}$ ) is related to the requested increase of the commercial speed. Its cost is assumed equal to 75.5 euro/truck according to available commercial rates, considering an average distance of $400 \mathrm{Km}$ between the warehouse and the destination.

- Travel cancellation, it is a save of money related to the fact that if a unit cannot reach the destination in a quality level $>\mathrm{QL}$, it is not worth to pay for the journey cost. The journey cost of a freight unit (travel cost ${ }_{i}^{\text {normal speed }}$ ) is assumed equal to 77 euro/unit. We assumed that the total travel cost is equal to 1000 euro and that in the journey 13 freight units are transported. 1000 euro is the total travel cost of a $400 \mathrm{~km}$ journey performed by a truck with gross vehicle weight included in $(11,5 t-26 t)$. The total travel cost has been assessed with the data provided by the Italian Observatory on road freight transport activities (http://www.mit.gov.it/mit/mop_all.php?p_i $\mathrm{d}=10640$ ) and assuming that variable costs constitute about $44 \%$ of the total travel cost (Jacyna and Wasiak, 2015).

\subsection{Simulation output}

The performance of each scenario is evaluated in terms of the risk at which the company is exposed during the reference period, evaluating the $\mathrm{R}^{\mathrm{S}}$ value and the risk matrix composed by $H_{d c}$ and $D_{d c}$ classes. A number of 1000 iterations have been carried out for both the scenarios, in order to satisfy the stopping criteria defined in Cepolina et al. (2019b).

\subsubsection{Current scenario: NO RFID-TTI}

The obtained risk value for the current scenario is:

$$
R^{S}=4735.5 \text { euro }
$$

The resulting risk matrix is displayed in Table 2 . It is possible to observe that for the $41 \%$ of cases the class of damage is "Severe" corresponding to a total damage level higher than 5001 euro. In this scenario all the errors generated during simulation cannot be mitigated leading to the complete freight unit loss and the entire transport cost.

Table 2: Risk matrix for the current scenario (no RFIDTTI implementation)

\begin{tabular}{|c|c|c|c|c|c|c|}
\hline & \multicolumn{5}{|c|}{$H_{d c}$} \\
\hline & & 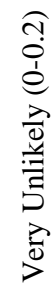 & 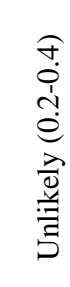 & 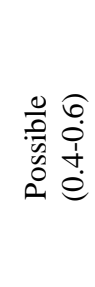 & 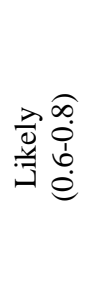 & $\begin{array}{l}\widehat{0} \\
0 \\
0 \\
0 \\
0 \\
0 \\
0 \\
0 \\
0 \\
0\end{array}$ \\
\hline \multirow{5}{*}{$D_{d c}$} & Negligible & & 0.25 & & & \\
\hline & Minor & 0 & & & & \\
\hline & Moderate & 0 & & & & \\
\hline & Significant & & 0.34 & & & \\
\hline & Severe & & & 0.41 & & \\
\hline
\end{tabular}

\subsubsection{Scenario D: RFID-TTI implementation}

The obtained risk value for the scenario with RFID_TTI implementation is:

$$
R^{S}=2372.7 \text { euro }
$$

The resulting risk matrix is displayed in Table 3 .

Table 3 Risk matrix for the scenario D (RFID_TTI implementation)

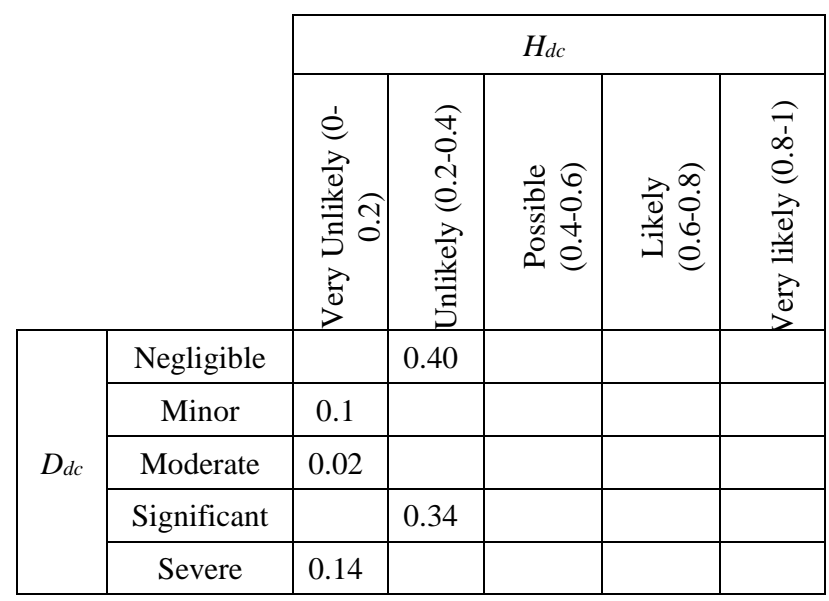

The frequency of the number of time that the total damage level falls within the class "severe" drops down to $14 \%$. At the same time the frequency of "negligible" damages increases from $25 \%$ to $40 \%$, while for the class 
"significant" the frequency remains the same and equal to $34 \%$. The resulting risk reduction obtained with this RFID-TTI implementation is about 50\%.

Figure 7 shows the error distribution in 1000 runs, while Figure 8 shows the number of times that the system has selected each kind of mitigation action.

When type pp error takes place (125 times) the possible mitigation action is "product rejection" and can be applied in all the cases (125 times).

In case of "type c" error, the "express delivery" mitigation action is successful in 237 cases of 485 (49\%), in all the other cases "travel cancellation" is applied.

In case of "type s" error, "accelerated delivery" is successful 394 times of 801 (49.2\%), otherwise, as for type c error, travel cancellation is applied.

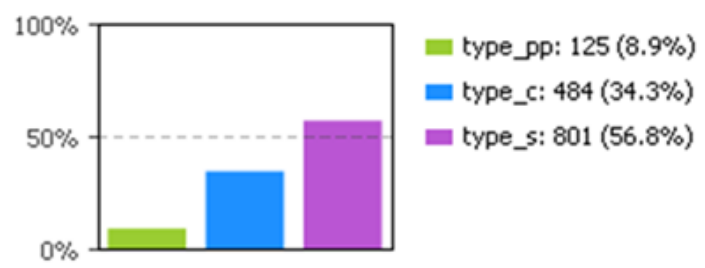

Figure 7: Scenario D, error occurrences in 1000 iterations

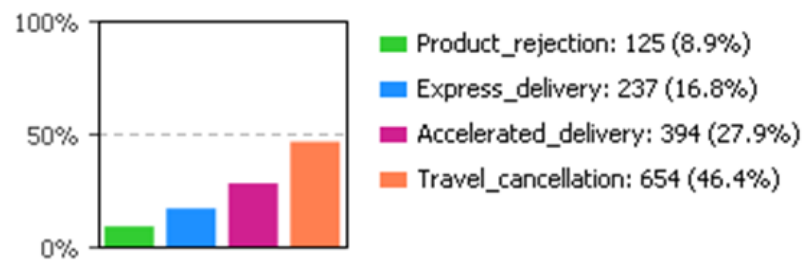

Figure 8: Scenario D: Mitigation action distribution (1000 iterations).

\subsubsection{Scenario D: implementation costs}

The costs can be divided in to two groups: warehouse implementation costs and tag's costs for each freight unit. The cost of each RFID reader is in the range 1200 euro ( 2 antennas) -1600 euro (4 antennas, if needed). Installation costs have to be added for each portal and can be between 300 and 600 euros. The cost of each RFID-TTI tag with temperature sensor is between 9 euro and 15 euro, depending on order quantities, much higher than the cost of a single RFID tag that is between 0.070.1 euro. It is possible to notice that tags with sensors are quite expensive, but it is important to underline that they can be reusable a very high number of times within the battery duration. Therefore, the average cost of initial hardware implementation for Scenario $\mathrm{D}$ can be considered equal to 5550 euro ( 3 portals). Whilst the average cost for 364 RFID-TTI tags is about 4368 euro. The cost of the middleware, needed to communicate tag data to the software, is included in previous costs, while the costs needed for the software are not displayed since can be much variable in relation with the amount of data managed, how data are stored and the integration with the company management software.

\section{CONCLUSIONS}

Traceability represents a major concern in supply chains of perishable products. Fresh goods contamination is a critical issue since the increasing complexity of supply chains makes these events more likely to happen (Bruzzone et al. 2014). Progress enables complex and integrated monitoring systems based on Internet of Things, continuous monitoring and real-time alerting. However, the adoption rate of these innovations is not fast enough due to the need of expensive equipment and a robust digital infrastructure (Gallo et al. 2018).

Montecarlo simulation is used to estimate the value of damage in presence of uncertainty. A similar approach in the food industry has been applied by Tufano et al. (2018).

The present study shows how the introduction of RFIDTTI technology allows a risk reduction of about 2363 euro (about 50\% with respect to the current scenario) for the management of 364 freight units, having the possibility of mitigate human error consequences with "express or accelerate delivery" and travel cancellation if all possible mitigation actions don't allow to guarantee the suitable quality level during the logistic chain.

As far as implementation costs is concerned, the possibility of reusing RFID-TTI tags and who is in charge of applying tags to the units (producer, carrier...) become crucial aspects to discern how much the technology can be convenient for the carrier company.

\section{ACKNOWLEDGMENTS}

The proposed paper has been developed within the "Equality4Logistics" project which has been co-funded by the Tuscany Region, Italy (POR FESR 2014-2020).

\section{REFERENCES}

Bruzzone, A.G, Longo F., Massei M., Nicoletti L., Agresta M. (2014). Safety and security in fresh good supply chain International Journal of Food Engineering Volume 10, Issue 4, 1 December 2014, Pages 545-556

Cepolina E. M., Farina A. (2015) A new urban freight distribution scheme and an optimization methodology for reducing its overall cost, European Transport Research Review Open Access Volume 7, Issue $1,14 \mathrm{p}$

Cepolina, E. M., Cangialosi E., Giusti I., Aquaro D. (2019a) A methodology for assessing RFID technology impact on logistics efficiency. Simulation of a real case study, Submitted to International Journal of Production Research. 
Cepolina, E. M., Giusti I., Cangialosi E., Aquaro D., Caroti G., Piemonte A. (2019b) Mitigation of human error consequences in general cargo handler logistics: impact of RFID implementation. Submitted to the special issue: "Industrial and Transport Business Dynamic Ecosystems for Decision Making" of the Computers \& Industrial Engineering.

Cepolina, E. M., Giusti I., Menichini F., Aquaro D., Caroti G., Piemonte A (2018) Simulative analysis for performance measurement of RFID implementation in cargo handler logistics, Proceedings of 20th Int. Conference on Harbor, Maritime and Multimodal Logistics Modeling and Simulation, HMS 2018, Held at the International Multidisciplinary Modeling and Simulation Multiconference, I3M 2018, pp. 44-51.

Cepolina, E.M. (2016) The packages clustering optimization in the logistics of the last mile freight distribution International Journal of Simulation and Process Modelling, 11 (6), pp. 468-478.

Gallo, R. Accorsi, R. Manzini, D. Santi, A. Tufano (2018) Improving integration in supply chain traceability systems for perishable products. Proceedings of the International Food Operations and Processing Simulation Workshop XI ISBN 97888-85741-18-8; Bruzzone, Longo, Piera and Vignali Eds. pp 28-35.

Jacyna M. and Wasiak M. (2015) Costs of road transport depending on the type of vehicles. Combustion Engines. 2015, 162(3), 85-90. ISSN 2300-9896

Kang Y. S., Jin H., Ryou O., Lee Y. H. (2012) A simulation approach for optimal design of RFID sensor tag-based cold chain systems. Journal of Food Engineering 113 pp. 1-10

Molfino R., Zoppi M., Muscolo G.G., Cepolina E. et al. An Electro-Mobility System for Freight Service in Urban Areas. International Journal of Electric and Hybrid Vehicles7(1) DOI: 10.1504/IJEHV.2015.068932, Inderscience Publishers, 2015, pp.21. hal-01090996

Sahin F., Baba M.Z., Dallery Y., Vaillant R. (2007) Ensuring supply chain safety through time temperature integrators. International Journal of Logistics Management, 18 (1), pp. 102-124

Sloof, M., Tijskens, L.M.M., Wilkinson, E.C. (1996). Concepts for modeling the quality of perishable products. Trends in Food Science and Technology 7, 165-171.

Tijskens, L.M.M., Evelo, R.G. (1994). Modeling color of tomatoes during postharvest storage. Postharvest Biology and Technology 4, 85-98.
Tijskens, L.M.M., Polderdijk, J.J., 1996. A generic model for keeping quality of vegetable produce during storage and distribution. Agricultural Systems 51 (4), 431-452.

Tufano, R. Accorsi, A. Gallo, R. Manzini (2018) Simulation in food catering industry. A dashboard of performance indicators. Proceedings of the International Food Operations and Processing Simulation Workshop XI ISBN 978-88-85741-18-8; Bruzzone, Longo, Piera and Vignali Eds. pp 20-27

Wang L., Kwok S.K., Ip W.H. (2010). A radio frequency identification and sensor-based system for the transportation of food Journal of Food Engineering 101 120-129129 


\title{
A TESTING PROCEDURE OF A DIGITAL APPLICATION FOR SAFETY IMPROVEMENT IN A BEVERAGE PLANT
}

\author{
Giuseppe Vignali ${ }^{(1)}$, Nicolas Guareschi ${ }^{(1)}$, Letizia Tebaldi ${ }^{(1)}$, Francesco Longo ${ }^{(2)}$, Luciano Di Donato ${ }^{(3)}$, Alessandra \\ Ferraro $^{(3)}$, Eleonora Bottani ${ }^{(1)}$ \\ (1) Department of Industrial Engineering, University of Parma, Parco Area delle Scienze 181/A, 43124 Parma (Italy), \\ (2) DIMEG, University of Calabria, Via P. Bucci, Cubo 44C, third floor via p bucci, Rende, Cosenza, 87036, Italy, \\ (3) Innovazioni Tecnologiche e Sicurezza degli Impianti, Prodotti Ed Insediamenti Antropici, Istituto Nazionale \\ Assicurazione Contro Gli Infortuni sul Lavoro, Roma, Lazio, Italy
}

giuseppe.vignali@unipr.it, nicolas.guareschi@studenti.unipr.it, letizia.tebaldi@unipr.it, f.longo@unical.it, 1.didonato@inail.it, ale.ferraro@inail.it, eleonora.bottani@unipr.it

\begin{abstract}
Safety at the workplace is one of the most relevant issues for companies, due to the high number of accidents happening every year, some of which even deadly. Despite that, this number is decreasing thanks to continuous research and to an increasing application of safety procedures and devices. In line with that, the project presented in this work intends to develop and evaluate a new solution to improve operators' safety, at a reasonable cost (including adoption and use). The usage of wearable systems (smart-glasses and smartwatches) will improve the efficacy of the solutions previously tested on mobile devices like tablets and smartphones. Although no new devices were developed, the project required the creation of a new software tool, in which a great amount of information was inserted to allow its correct functioning.

The main aim of this work is to create a testing procedure to evaluate the impact of this solutions on the employee's safety. This is extremely important to demonstrate the efficacy of new industry 4.0 applications.
\end{abstract}

Keywords: Augmented Reality, work safety, Mixed Reality; case study, Industry 4.0.

\section{INTRODUCTION}

One of the last polls made in the EU28 (EUROSTAT 2018) shows that in 2015 there were more than 3 million of accidents (causing more than four days of absence from work) with almost 4 thousands deaths. These numbers only refer to Europe, which is considered as a reference zone due to the high level of technology and attention paid to safety and, also, where advanced solutions (such as that described in this study) can be easily applied. Nevertheless, there is no doubt that safety concerns are global problems, having a greater impact on the third-world and the developing economies, where culture and laws do not consider workers' conditions. Globally, about 340 millions of accidents and 160 millions of work-related illness are observed every year, with 2.3 million of deaths (International Labour Organization 2008).
Conventional solutions aiming at increasing safety are not always able to completely remove risks, mainly due to the implicit nature of works itself, and also to the operators' behaviour or their level of training (Leão and Costa 2019). There are also further aspects to be taken in account: has the system been designed with a high level of security? (Kolbachev and Salnikova 2019). The level of safety was adequate time ago; is it safe enough now? (Song and Yang 2019).

With the purpose of enhancing the operators' safety, a research project, W-Artemys (Wearable augmented reality for employee safety in manufacturing systems), was started by some Italian institutions and aimed at introducing the new technologies offered by the wellknown fourth industrial revolution in the safety context. More precisely, the aim of the project is to propose new solutions based on Augmented Reality (AR) which can help workers while performing their tasks directly on the machinery; the support of AR is expected to help reduce errors and accidents. This is particularly the case for complicated procedures, where employees are likely to make mistakes or to forget steps, thus causing machine downtime and, consequently, unplanned production standstill.

AR was selected among the Industry 4.0 technologies for its characteristic of being smart: indeed, it can be easily installed on handy or wearable tools, such as tablets, smartphones or smart glasses; the use of these devices is immediate and understandable, and their cost is quite affordable (Bottani and Vignali 2019). Whether (or not) the implementation of AR is appropriate in the specific context under examination can be assessed thanks to a framework developed by Rosi et al. (Rosi, Vignali and Bottani 2018) and further developed by Bottani et al. (Vignali, et al. 2019).

On the basis of the premise above, the aim of this paper is to discuss the implementation challenges for a AR application intended to improve the safety level at the workplace and to detail a procedure for testing the effectiveness of the tool developed. As such, this study can be useful to guide similar implementations of AR for safety improvement in industrial contexts. 
The remainder of the paper is organized as follows. Section 2 provides an overview of the W-Artemys research project, in which this study has been carried out. Section 3 details the testing procedure for the AR solutions. Section 4 describes the expected benefits as well as the possible issues arising from the implementation of the tool. Section 5 concludes and indicates future research activities.

\section{THE W-ARTEMYS PROJECT}

\subsection{Overview}

The W-Artemys project is multi-disciplinary in nature, as it required different knowledge and competences in various engineering fields; this is why the project required the collaboration of different universities. With the financial support of INAIL (Italian insurance institute for work-related accidents), the University of Parma (UNIPR), University of Genova (UNIGE) and University of Calabria (UNICAL) started the development of $\mathrm{W}$-Artemys platform. This platform collects mainly three different systems, i.e.: a database, a vocal assistant and an augmented reality tool. The software has been designed to be implemented on commercial devices (tablets, smartphones or smart glasses), thus avoiding the need to develop an ad hoc physical support. The timetable of the project was based on two years of activity, but an extension of further six months have been requested and approved by INAIL.

Table 1 shows the activity planning, including the tasks completed and those currently in progress.

Table 1: Work plan for the development of the WArtemys system

\begin{tabular}{|l|l|l|l|l||}
\hline & & & & \\
\hline
\end{tabular}

The W-Artemys platform has a modular architecture: based on the main software (which manages the database information), the vocal assistant, the alarms management system and the augmented reality system are added as plug-in. The plug-in system was chosen to allow the project partners to work independently on the $\mathrm{W}$ Artemys platform, even if the system itself was not completed. This logic is used for most of the minor options included in the project, like the $\mathrm{QR}$ code generator and reader, the search tool or the pictures and pdf upload module. The QR code generator can be used to create QR codes to be placed in specific parts of the machine; when read by the device's camera, the code directly links to the related argument or document. The search tool allows to use specific keywords to find elements, avoiding a manual screening of the WArtemys' database. During his activity, the operator can also upload useful documentation, such as pictures or $\mathrm{pdf}$ files. All these elements have been designed to help the employee in his activity, to perform his tasks avoiding errors, thus increasing the safety level without jeopardising his efficiency (operation time).

In the last months were also added specific systems to manage the alarms of the set of equipment and to use the AR to help the operators during one specific activity, which was selected due to its complexity (bottles size changeover).

\subsection{Software structure}

As can be seen in Table 1, the first months of the project were spent for the development of the main software architecture, i.e. the basic program where all the remaining elements will be installed. This work was mainly done by UNICAL. Once the structure of the software tool was sketched, pieces of information about the machines to be tested were collected in order to fill the database. Two companies, both based in Parma, were involved in the application of the tool and will collaborate to the testing phase: GEA Procomac (GEA engineering for a better world s.d.) and Parmalat (Parmalat 2019). GEA Procomac is a market leader in the filling machines field and is the manufacturer of the machine selected for the application of the W-Artemys tool; Parmalat is one of the main beverage companies around the world and is the user of the selected machine. An aseptic filling monoblock, manufactured by GEA Procomac and located at the Parmalat site, was chosen as case study. A detailed description about the machines themselves has been presented in a previous work (Vignali, et al. 2019); for completeness, a short description will be reported also in section 2.3.

Once the W-Artemys architecture was sketched, UNIPR started filling the database by entering information about the selected machine. This activity required to convert the information collected in a format compatible with the software structure; more precisely, information entered and files uploaded had to be clear and easy to read and to understand by the user. It was also necessary to create a precise logic to organize all the files inside W-Artemys platform; this activity was carried out in a previous work (Vignali, et al. 2019).

The first step to create the database was to examine all the machines' manuals in order to extrapolate the relevant information and determine how to organize it. To comply with the tree structure of W-Artemys and create a user-friendly interface, operations were grouped into different sets, with intuitive names.

Overall, the amount of information retrieved was organized in around 200 groups and files. For any new element created there is the need to fill in many information (such as description, keywords, reference picture, reference colour) and to upload the relevant files. The vocal assistant was activated at the beginning of 2019. The function of this plug-in is to allows rapid search and to retrieve the relevant groups of elements as results, or directly answer the questions raised by the user. For the system to function, it is necessary to insert a set of keywords for every block. The choice of the 
keywords is crucial for the correct functioning of the system: indeed, only if inserting specific keywords, the system is able to retrieve the required item as answer. In line with this principle, several possible keywords were inserted in every research field, including synonyms, so as to allow the operators to use different words and obtain the answer they are looking for. With respect to the answers themselves, they need to be created for each single question, in every element, in such a way that the vocal assistant is able to give back the information searched.

The last months were focused on the implementation of the alarms management system, which is the last element required before implementing the AR tool. The general structure of the alarm management system was discussed together with all the project partners. Implementing this plug-in requires the $\mathrm{W}$-Artemys software to be real-time connected with the machine's database; this is actually one of the main obstacles for this module. Indeed, nowadays companies are increasingly concerned about cyber-attacks, and also, old machines are not predisposed to be connected to the internet. When an internet connection is available, firewalls are typically installed and only few and trusted connections are allowed. To allow the alarms management system to work, information on the state of the aseptic filling monoblock should be exchange via web. This kind of information exchange is mandatory due to the different physical location of the W-Artemys server and the machine server: the first one is located in the UNICAL's servers and the second one is at the company's site. After dedicated meetings, the project partners came to the conclusion that a read-only access to the alarms database could be provided and that a mirroring server should be implemented. This compromise solution allows the $\mathrm{W}$ Artemys tool to identify the active alarms and send notifications to the operators. To this end, two main tasks have been carried out:

- First, has been created a table linking each alarm code to the corresponding restoring procedure (in W-Artemys). This should allow UNICAL to link the alarm of the monoblock to the right solving procedure;

- Second, as far as the software is concerned, has been implemented the alarms plug-in.

Although the table linking alarms and solution procedures has a quite simple structure, its creation was not so immediate; indeed, machines such as those considered in this study contain hundreds of sensors and, consequently, generates hundreds of different alarms or warning. Thanks to the guidance of GEA Procomac, all the alarms generated by the monoblock were collected: their final number totals more than nine hundred alarms and warnings. From an analysis of the resulting list, three main points were noticed:

- Not all the alarms turned out to be relevant for the purpose of this study, as they are not included in the machines' manuals; their code has been therefore skipped in the table;

- Some operations correspond to more alarms codes generated by the machine;

- Some alarms codes have no description, which makes it difficult to understand their object.

A preliminary screening of the alarms was made by looking at the first sixty rows of the alarm table generated by the monoblock. This screening was intended to quickly create some data to be inserted in the alarms management system for testing purpose. The choice to create a list of a subset of alarms was motivated by the following considerations:

- The ongoing development of the alarms management system involves uncertainty about the logics behind them. Hence, a pre-test phase of the alarm management tool should be carried out with a subset of alarms, to try its functioning;

- Related to the previous point, because of the high number of alarms, the full list of them will be more effectively handed when the alarm management module will have been debugged.

Based on this issue, the alarms management module has been created and it was able to collect from MSql server 2008 R2 only the selected alarms and to display them on the mobile devices (Tablets and smartphones), where the W-Artemys have been installed. Nowadays the notifications of the alarms appear out of the app (but in the same devices) and then the operators should find the solution inside the W-Artemys app. A test will be done also using smartwatches as wearable devices, able to receive the alarms, while other devices like tablets or smartwatches will help to solve the problem on the set of equipment.

Finally, the AR app has been realizing both on the wearable devices (smart-glasses) and on simple mobile devices (tablets and smartphones). This application is made in order to help the operators, which actually work on the equipment, to do also difficult activities such as the bottle size changeover (now it is performed by specialized maintenance operators). The AR application needs in this case the usage of tags in order to understands the exact position with the aim to add digital information on the real images. This functionality is implementing in both the wearable and mobile devices, with the differences that in wearable solutions the act to skip or validate the phases is different from that of mobile systems (tablets and smartphones need only to press a key).

Section 3 will describe a first series of tests that will be carried out on the whole system. Nonetheless, some specific tests on the different plug-ins of the W-Artemys tool also need to be carried out, to check their performance singularly. This standalone and internal test has been already done with the W-Artemys modules 
developed up to now. This procedure allowed to check every aspect of every module in detail, so as to arrive at the final test with all components working properly.

\subsection{Tested machine description}

As mentioned earlier, the machine chosen for the implementation of the W-Artemys tool is an aseptic filling monoblock. Despite its name, the monoblock consists of five machines. Following the production flow, once the bottles enter the monoblock, they are processed by the sterilizing machine, whose main aim is to sterilize the bottles, inside and outside, in such a way to destruct the bacterial count without interacting with the plastic. Hot peracetic acid is used to this end.

At the exit of the sterilizing machine the bottles require a washing process to remove the residue of peracetic acid. The washing machine is similar to the previous one in its structure, but instead of a cleaning fluid, sterilized water circulates inside it.

Once washed, the bottles enter the filling machine. A critical process is made here: the sterilized product from the production plant is injected inside the bottle, and the environment must be as clean as possible to avoid any contamination of the product.

Once filled, the bottles reach the capping machine. Caps, previously sterilized in a machine similar to the steriliser, are screwed with a precise torque on bottles. This last operation ends the process, which is summarized in Figure 2.

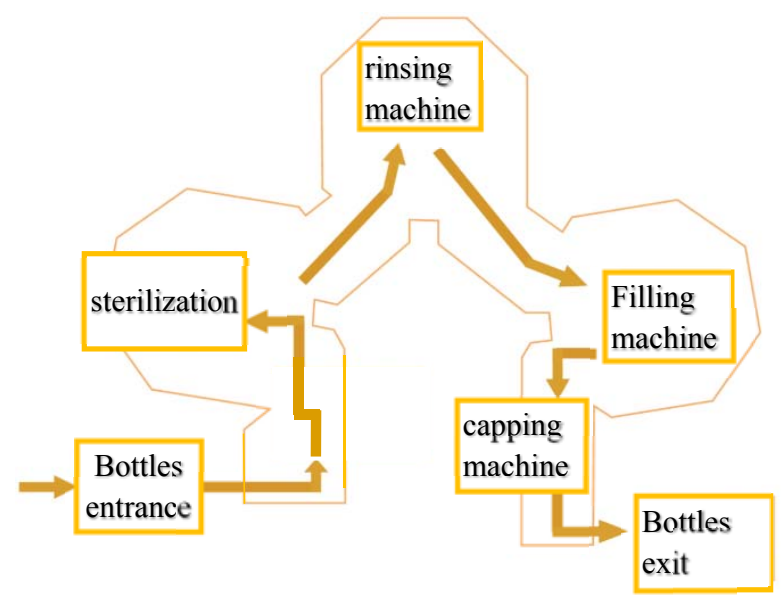

Figure 2: Production flow of the aseptic filling line.

Almost all the processes take places in an aseptic environment; in this regard, when the bottles exit from the sterilizing process, the air inside the machine has to be purified too. To this end, a series of ventilators with air filters are installed on the machine. This system allows to keep the pressure inside the monoblock higher than the ambient pressure, meaning that no particles will enter the machine and contaminate the product or bottles. These strict conditions of cleanliness are guaranteed by the manufacturer for a limited amount of time only; every one hundred hours, it is necessary to perform a Clean-inPlace (CIP) and a Sterilising-in-Place (SIP) process in order to restore the initial conditions.
A more detailed description of the monoblock can be found in (Rosi, Vignali and Bottani 2018) and (Vignali, et al. 2019).

\section{TESTING PROCEDURE}

According to some preliminary analyses carried out with Parmalat, the format changeover on the whole line was chosen as operation to be converted in $\mathrm{AR}$ and, consequently, tested. Indeed, the bottling line in question deals with four different bottle formats and the procedure, performed when the five machines are switched off, generates a significant downtime.

Tests will be performed by UNIPR and are planned between November and December 2019. This timing is due to the seasonality of products manufactured by Parmalat (which occupies the plant full time from April to October) and to the availability of the W-Artemys system, which is expected to be complete in September 2019.

Four employees from Parmalat, preferably inexpert, will be involved in the testing phase. They will be introduced to the project and then trained on the devices they will have to deal with. Other four employees from Gea Procomac will be selected in order to understand the differences among these and those of Parmalat.

Between the total forty-three activities to be carried out during the format changeover, by removing the redundant ones (i.e. those that are repeated several times), the following eleven resulted:

1. Adjusting the height of the inlet conveyor;

2. Disk rotation;

3. Guide pin and guide regulation;

4. Bottles stop pads replacing and regulation;

5. Replacement of the entrance scroll;

6. Guide adjustment;

7. Starwheel replacement;

8. Guide replacement;

9. Dowel replacement;

10. First sector of the guide rotation;

11. Second sector of the guide rotation.

Some of these will be selected based on the following criteria: ease of investigation from the external part of the equipment, repetitiveness of operation on the various machines, utility of the technological solution for the specific operation. Indicatively the duration of the operations must not exceed 15-20 minutes for practical reasons.

The aim of the tests will be to evaluate the effectiveness of the AR solution during the execution of the abovementioned activities. To do this, each task will be repeated four times by the four operators of GEA 
Procomac and Parmalat with the support of four different tools:

a. Printed manual;

b. Tablet and wearable device (without AR implementation);

c. Tablet and wearable device (with AR implementation);

d. Voice assistant.

Tests are planned so that for some phases of format changeover operated by a single person, all the four tools will be used by the same person; in this way, results can be more objective and not affected by the specific user experience (e.g., with AR devices or vocal assistant).

Each repetition will be timed through a manual digital chronometer and supervised.

As far as the key performance indicators, we will consider as quantitative outputs the time spent for completing the operations and the number of errors made by the users during the execution of the tasks. Once observations will be recorded, statistical analysis can be considered. As we deal with a test carried out for one factor (the AR) at four different levels (the four tools), an F-test can be performed, i.e. the analysis of variance (ANOVA). Design Expert release 7.1 software package (Stat-Ease, Inc., Minneapolis, USA) will support this data processing.

Finally, through a survey we intend to present in retrospect to the operators involved, we will also acquire qualitative feedbacks on the users' response, e.g. on the ease of usage or perception of safety. To this end we plan to use the unified theory of acceptance and use of technology (UTAUT), which is a technology acceptance model formulated by Venkatesh et al. (Venkatesh, et al. 2013) on the basis of a review of the existing theory acceptance models. The UTAUT model aims to explain user intentions to use an information system and subsequent usage behaviour. The model takes into account four core determinants of intention and usage (i.e. 1) performance expectancy, 2) effort expectancy, 3) social influence, and 4) facilitating conditions), and up to four moderators of key relations.

\section{CONCLUSIONS AND IMPLEMENTATION CHALLENGES}

One of the main challenges identified in the whole project is the creation of a well compiled database. Indeed, information on the operations to be converted in AR are often not sufficiently detailed in the machines' manuals. As mentioned before not only operations are troublesome to be collected but also all the information that must be included inside the W-Artemys. In general, from a practical perspective the development of this kind of solution needs a huge amount of manual work, which could be even greater if the application is to be replicated on different machines.
Again from a practical point of view, a further difficulty encountered was to link the alarms codes with the corresponding description in the manuals. Indeed, the internal database contains all the alarms generated by the machine, but these alarms are often redundant or unclear in their name; this makes it difficult to directly link them to the correct restoring procedure. A company technician (in our case a GEA Procomac manager) was involved in this phase to explain the meaning of the machine alarms.

From a systems' perspective, an alarms management system, as the one designed in W-Artemys, requires (at least now) an internet connection, in order to read the alarms status of the machine. This requires the possibility for the machine to put and share information online, and the company's availability to allow this information exchange.

Based on these peculiarities, in conclusion, the activities performed have shown how it is complex to implement industry 4.0 solutions on an existing machine due to in particular the use of updated version of software and the need of high performances of informatics hardware. All these activities could be easily done on a new machine where all the systems could be based on the same operating system.

\section{ACKNOWLEDGEMENTS}

This research was funded by INAIL (Istituto Nazionale per l'Assicurazione Contro gli Infortuni sul Lavoro), the Italian National Institute for Insurance against Accidents at Work, under the project "W-Artemys" (Wearable augmented reality for employee safety in manufacturing systems) - BRIC ID38.

\section{REFERENCES}

\section{BIBLIOGRAFIA}

Bottani, Eleonora, and Giuseppe Vignali. "Augmented reality technology in the manufacturing industry: A review of the last decade." IISE Transactions 51, no. 3 (2019): 284-310.

EUROSTAT. Accidents at work statistics. june 2018. https:/ec.europa.eu/eurostat/statisticsexplained/index.php/Accidents at work statis tics\#Number_of_accidents (accessed luglio 17, 2019).

GEA - engineering for a better world. s.d. https://www.gea.com/it/company/at-aglance/our-company/index.jsp.

International Labour Organization. World Statistic: The enormous burden of poor working conditions. 2008. https://www.ilo.org/moscow/areas-ofwork/occupational-safety-andhealth/WCMS_249278/lang--en/index.htm (accessed july 17, 2019).

Kolbachev, Evgeny, and Yulia Salnikova. "Socially oriented design of technical systems and objects: Safety and accident prevention." International Conference on Safety 
Management and Human Factors. Washington D.C.: AHFE, 2019. 317-326.

Leão, Celina P., and Susana Costa. "Safety training and occupational accidents - is there a link?" AHFE International Conference on Social and Occupational Ergonomics. Washington D.C.: AHFE, 2019. Pages 536-543.

Parmalat. chi siamo. 2019. https://www.parmalat.it/chisiamo/ (accessed 01 29, 2019).

Rosi, Giovanni, Giuseppe Vignali, and Eleonora Bottani . "A conceptual framework for the selection of an"Industry 4.0" application to enhance the operators' safety: the case of an aseptic bottling line." 2018 IEEE International Conference on Engineering,Technology and Innovation (ICE/ITMC). Stuttgart: 2018 IEEE International Conference on Engineering,Technology and Innovation (ICE/ITMC), 2018.

Song, Yang, and Xuefei Yang. "Theory of safety quantification and equivalence oriented industrial system." AHFE International Conference on Safety Management and Human Factors. Washington D.C.: AHFE, 2019. 143152.

Venkatesh, V., M.G. Morris, G.B. Davis, and F.D. Davis. "User Acceptance of Information Technology: Toward a Unified View." MIS Quarterly 27, no. 3 (2013): 425-478.

Vignali, Giuseppe, et al. «Development of a 4.0 industry application for increasing occupational safety: guidelines for a correct approach.»ICE/IEEE ITMC international conference on engineering, tecnology and innovation. Sophia Antipolis: ICE/IEEE ITMC, 2019.

wikipedia. Industry 4.0. 15 july 2019. https://en.wikipedia.org/wiki/Industry_4.0 (accessed july 17, 2019).

\section{AUTHORS BIOGRAPHY}

Giuseppe VIGNALI is an Associate Professor at University of Parma. He graduated in 2004 in Mechanical Engineering at the University of Parma. In 2009, he received his PhD in Industrial Engineering at the same university, related to the analysis and optimization of food processes. His research activities concern food processing and packaging issues and safety/security of industrial plant. Results of his studies related to the above topics have been published in more than 100 scientific papers, some of which appear in national and international journals and conferences.

Nicolas GUARESCHI has taken a bachelor degree in mechanicals engineering and a master degree in 2019 on Engineering for Food Industry Equipment. From December 2018 he has a scholarship with CERIT, a research centre of University of Parma. During this period, he is working mainly on a project to recovery food waste and on the development of an industry 4.0 related system to improve safety during manual works. Thanks to this last project in 2019 was a co-author of an article presented during the 2019 IEEE International Conference on Engineering, Technology and Innovation.

Letizia TEBALDI is a first year Ph.D. student in Industrial Engineering at the Department of Engineering and Architecture of the University of Parma. She graduated cum laude in March 2018 in Management Engineering, presenting a dissertation on a systematic literature review on sustainable supply chain and innovation. Her research interests are mainly on logistics and supply chain management; sustainable supply chain; analysis and optimization of supply chain; industry 4.0 for operators' safety.

Francesco LONGO received his Ph.D. in Mechanical Engineering from University of Calabria in January 2006. $\mathrm{He}$ is currently Assistant Professor at the Mechanical Department of University of Calabria and Director of the Modelling \& Simulation Center Laboratory of Enterprise Solutions (MSC-LES). He has published more than 160 papers on international conferences and journals. His research interests include Modeling \& Simulation tools for training procedures in complex environment, supply chain management and security. $\mathrm{He}$ is Associate Editor of the "Simulation: Transaction of the society for Modeling \& Simulation International". For the same journal he is Guest Editor of the special issue on Advances of Modeling \& Simulation in Supply Chain and Industry. He is Guest Editor of the "International Journal of Simulation and Process Modelling", special issue on Industry and Supply Chain: Technical, Economic and Environmental Sustainability. He is Editor in Chief of the SCS M\&S Newsletter and he has served as General Chair and Program Chair for the most important international conferences in the simulation area.

Luciano DI DONATO graduated in 1992 in Electrical Engineering at the University of Federico II. He had a previous position as technical director for an electrical installation company and played professional service in the field of electrical construction sites. Since 1997 he is a researcher in INAIL and since 2015 he is Responsible of Machines and work equipment Lab in Department of Technological Innovation. His main fields of research concern safety of machinery and working equipment, the critical issues of electrical equipment of machines and the issue of defeating, misuse and reasonably foreseeable misuse related to safety distances and safety devices. He is author of about fifty papers published in journals and many conference papers. He participated in many scientific committees and international meetings.

$\mathrm{He}$ is member of National and European technical working groups for safety of machines and confined space with or without pollution. He is a Chair Person of CEN TC 146 Packaging machines - Safety.

Alessandra FERRARO graduated in 2004 in Mechanical Engineering at the University of Roma Tre. 
Started professional experience providing maintenance services for a leading chemical company, since 2011 she is a researcher in INAIL Department of Technological Innovation. Her primary research interest is in safety of machinery and working equipment, focusing on the critical issues of machines for lifting of people and on the topic of defeating, misuse and reasonably foreseeable misuse. She is author (or coauthor) of papers in safety journals, she participated as speaker in many conferences, she is active in training on safety for technicians on the field.

Eleonora BOTTANI is Associate professor of Industrial Logistics at the Department of Engineering and Architecture of the University of Parma since September 2014. She graduated (with distinction) in Industrial Engineering and Management in 2002 and got her Ph.D. in Industrial Engineering in 2006, both at the University of Parma. Her research activities concern logistics and supply chain management issues. She is author (or coauthor) of more than 170 scientific papers (citations on Scopus $>1700 ; \mathrm{H}$-index $=19$ ), referee for more than 60 international journals, editorial board member of five scientific journals, Associate Editor for one of those journals, and editor-in-chief of a scientific journal. 


\title{
MODELLING THE GROWTH KINETIC OF SPOILAGE MICROORGANISMS IN A PACKAGED COW'S RICOTTA PROCESSED WITH HIGH PRESSURE
}

\author{
Stefanini Roberta ${ }^{(a)}$, Giuseppe Vignali ${ }^{(b)}$, Fabio Coloretti ${ }^{(c)}$ \\ (a),(b) Department of Industrial Engineering, University of Parma, Parco Area delle Scienze 181/A, 43124 Parma (Italy) \\ (c) Department of Agricultural and Food Science, Alma Mater Studiorum Università di Bologna, Viale Fanin, 44 - 40127 \\ Bologna
}

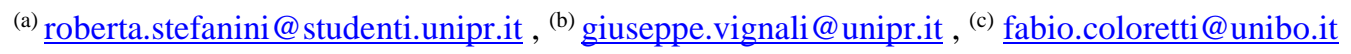

\begin{abstract}
Today consumers demand fresh foods without additives, preservatives and health risks: that is why non-thermal food preservation methods are receiving more interest, among them High Pressure Processing is able to avoid thermal degradation of food components, extend their shelf life and preserve colour, flavour and nutritional value. HPP is often used on dairy products because of its impact on physicochemical and sensory characteristics, its ability to improve their structure and texture and inactivate some microorganisms.

The aim of this work is to evaluate the effect of HPP on a packaged ricotta rich in Conjugated Linoleic Acid (CLA) and Omega-3, resulting from cows fed with linseed in the Parmigiano Reggiano area, and processed with a hydrostatic pressure of $600 \mathrm{MPa}$ for 5 minutes. The ultimate goal is to find a mathematical model able to show the treatment's effect on spoilage microorganisms that grow spontaneously in this product during a month of refrigerated storage.
\end{abstract}

Keywords: High Pressure Processing, Modelling, Ricotta, shelf life, Milk

\section{INTRODUCTION}

In the last years consumers demand fresh food with high sensorial and nutritional quality, but additive free, mildly processed, and especially safe from pathogenic and spoilage microorganisms. Therefore, food companies are challenging to develop food products with consumerdesired characteristics, using advanced thermal based technologies such as aseptic processing, microwave, ohmic and radio-frequency heating (Balasubramaniam et al. 2015). Moreover, the adoption of cleaner condition during the packaging phase could help to increase the shelf life of products (Bertolini et al. 2016). The major advantage of thermal treatment is the inactivation of pathogenic and spoilage microorganisms, with the consequent increasing of food shelf life, but it affects product's quality as nutritional value and color, disrupts vitamins and changes food flavor (Mosna and Vignali 2016). Thus, non-thermal methods have been developed such as irradiation, pulsed electric field, UV and High Pressure Processing (HPP) that has been recognized as one of the more relevant and frequently applied alternative techniques to conventional thermal processing.

The non-thermal pasteurization effect of high pressure on foods has been known since the $19^{\text {th }}$ century: in 1899 Hite used hydrostatic pressure up to $600 \mathrm{MPa}$ as a tool to preserve milk, then in 1914 it was tested on vegetables and fruits, but the major revolution came in Japan by releasing the first high pressure processed product into market (Elamin et al. 2015).

Over the past 30 years many studies have been performed to understand advances of HPP and it has been successfully implemented in different type of food industries worldwide. Nowadays, it is used in Japan, United States and Europe for pasteurization of food products, and equipment installation are increasing in numbers: the most famous and important industries of HPP machines today are Avure Technologies and Hyperbaric.

The major type of industrial high-pressure operating system is the batch-one, in which the cycle is characterized by the loading, compression, holding, decompression and unloading phases. The equipment usually consists of a cylindrical pressure vessel and its closure, an intensifier pump to generate pressure and a material-handling system. The food product, previously sealed in flexible and water-resistant packaging (Lambert et al. 2000), is put in a cylindrical container, pushed and closed into the pressure vessel: a pressure medium, usually cold water, is pumped isostatically from its tank and once the desired pressure is reached, the pump is stopped by closing the inlet valves. The high pressure transmitted by water on foods is usually up to 400-600 MPa for 3 up to 30 minutes (Elamin et al. 2015). A variety of liquid and solid foods can be treated with batch application, but since pasteurization treatments do not typically inactivate bacterial spores, it is important to maintain pressure-pasteurized products under refrigerated storage after the treatment. In fact, bacterial spores are more resistant to high hydrostatic pressure than vegetative cells: they can be eliminated with repeated cycling between high and low pressures, but the risk is only the partial elimination of the germinated spores, that can cause food poisoning. Instead, HPP successfully destroys vegetative microorganisms thanks to irreversible change to the membranes and the 
disruption of nucleic acids and ribosomes. The consequent permeabilistation of the membranes and the leakage of the content involve the cell's death (Datta and Deeth 1999).

Thanks to the destruction of spoilage microorganisms, HPP extends the shelf life of some products up to 10 times. The consequence is that additives or preservatives are not necessary and foods are more natural. Moreover, with the destruction of pathogens as Listeria, Staphylococcus, Salmonella, Escherichia coli, the technology assures food safety and exportation in worldwide markets. Today different markets in the world sell a wide range of products treated with HPP: juices, beverages, vegetable, fruit, meat, seafood products, ready to eat meals, soups, sauces, infant foods and dairy products. In 2014 HPP food production exceeded 500 million kg (Elamin et al. 2015).

In general, the complexity of food and the wide variety of phenomena that occur under pressure make difficult to predict effects of HPP on foods. For these reasons, HPP conditions must be evaluated in each specific product. Many researchers studied HPP effects on dairy products: the treatment seems able to improve their structure, homogenizing and softening ricottas and cheeses. Moreover, it increases lightness and conserve food colour for a long time (Calzada et al. 2015). Also a great amount of data exist on the effects of the treatment on chemical and microbiological characteristics of dairy products (Datta and Deeth 1999; Devi et al. 2013; Okpala et al. 2009; Pega et al. 2018; Ribeiro et al. 2018; Wibowo et al. 2019).

However, the largest part of researches consists in inoculating some microorganisms in foods and evaluating their survival after the treatment at different pressures and times, in order to estimate the destructive power of HPP (Serment-Moreno et al. 2017; Mussa et al. 1999; Serment-Moreno et al. 2015; Chen and Hoover 2003). Instead, there are very few studies on the spontaneous growth of microorganisms in foods treated with High Pressure Processing (Giacometti et al. 2016). In the last years, in the Italian Parmigiano Reggiano area, some cows are fed with linseed rich in CLA and Omega 3: the nutritional value of their food is transmitted in their milk, and consequently in cheeses and ricottas produced from it. Since the advantages of HPP seem to be very promising on cheeses and dairy products, in this work the treatment was used on ricotta in order to maintain its nutritional value (Gutiérrez 2016) and simultaneously improve its shelf life. Ricottas processed with high pressure were stored in fridge with untreated ricottas and observed for 30 days: every 10 days some ricottas were analysed in order to study the spontaneous microbial growth. Finally, the influence of the treatment has been studied using primary models to describe the growth of spoilage microorganisms.

\section{MATERIAL AND METHODS}

Natural ricotta has a really short shelf life because of the $\mathrm{pH}$ above 6.0 and water activity between 0.974-0.991 that make this product an excellent growth medium for a wide range of microorganisms (Pala et al. 2016). Ricotta is created from the whey obtained from the milk: microbes may originate on the farm from the milking equipment, environment or employees. Even if the production process reach elevated temperature that kills psychrophilic and mesophilic bacteria, the heat-tolerant species could survive and cause deterioration (Rawat 2015). Moreover, ricotta is exposed to microbial secondary contamination due to equipment and processing environment if the hygienic rules are not well respected in the processing plant.

Spoiled ricotta may be safe to eat if there are no pathogens or toxins, but it is characterized by undesirable or unacceptable sensory modifications for human consumption as off-odours or flavours and visible changes in colour and texture. Instead, it may do not look bad even if it is severely infected by pathogenic bacteria, and for this reason bacterial contamination is more dangerous.

The main spoilage and pathogenic microorganism that can be found in ricotta are Enterobacteriacea, Listeria monocytogenes, Pseudomonas spp., Bacillus cereus, yeasts, moulds and lactic acid bacteria. There are many parameters that establish the admissible concentration of microorganisms in ricotta suitable for consumers and many standards methods to conduce the microbiological analyses. Firstly, in order to ensure the non-alteration of the food, the concentration of total aerobic mesophilic bacteria have to be less than $10^{8} \mathrm{CFU} / \mathrm{g}$. The optimum count in ricotta and soft cheese is $<10^{6} \mathrm{CFU} / \mathrm{g}$. Instead, if the number of bacteria is between $10^{6}$ and $10^{7} \mathrm{CFU} / \mathrm{g}$ it's microbiologically acceptable, but it denotes that the hygiene of cheese production must be improved. Thus, if the concentration is $>10^{7} \mathrm{CFU} / \mathrm{g}$ it is unacceptable for human consumption, and it means that the process must be rechecked from a microbiological point of view.

On the other hand, a satisfactory concentration of yeasts and moulds is $<10^{2} \mathrm{CFU} / \mathrm{g}$ (FCD 2009), but it is also acceptable between $10^{2}$ and $10^{3} \mathrm{CFU} / \mathrm{g}$.

The presence of Pseudomonas spp. (optimum if $<10^{6}$ CFU/g) and Bacillus cereus (optimum if $<10^{2} \mathrm{CFU} / \mathrm{g}$ ) has to be evaluated during or at the end of the productive process, while during the food shelf life is advisable to study the presence of Listeria monocytogenes (must be absent or $<100 \mathrm{CFU} / \mathrm{g}$ ) and Salmonella spp. (absent).

\subsection{Packaging and HP treatment}

Depending on the target markets, ricotta is packaged in different ways: it can be wrapped in food paper for the gourmet food store, while for the large-scale retails it is usually packaged in vacuum or in Modified Atmosphere Packaging (MAP) in order to extend its shelf life. On the other hand, High Pressure Processing seems able to increase shelf life of dairy products up to 4 or 5 weeks (Pega et al. 2018; Giacometti et al. 2016).

In previous researches (Ugolotti and Vignali 2018), ricottas packaged in MAP were suitable for 10 days, but in this work the desired shelf life was at least twice as much as reached before: for that reason the HPP was used. Using the EasyFrom machine by ILPRA (ILPRA 
EasyForm Machine) 16 thermoformed trays containing $500 \mathrm{~g}$ of ricotta were created. Trays were composed by $\mathrm{PET} / \mathrm{EVOH} / \mathrm{PE}$, with a depth of $20 \mathrm{~mm}$ and a little head space containing not MAP but atmospheric air.

The half part of the trays were treated at $600 \mathrm{MPa}$ for 5 minutes in Avure Technologies HP machine (HPP Machine QFP350L). Then, the 8 untreated and 8 HPP trays were refrigerated at $4^{\circ} \mathrm{C}$ for a month.

\subsection{Microbiological analyses}

Every 10 days (T0 $=0$ days, $\mathrm{T} 1=10$ days, $\mathrm{T} 2=20$ days, T3=30 days), 2 treated and 2 untreated trays were analysed in order to observe the concentration of spoilage microorganisms in ricottas, despite the conservation in the fridge was surely able to slow down their growth.

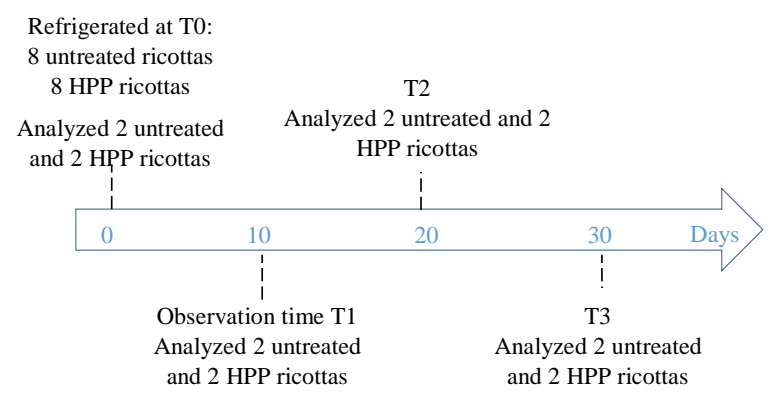

Figure 1: Planned Observation Times

The main object of study was the invasion by microorganisms such as moulds, yeasts and bacteria that cause spoilage in ricottas and were responsible for sensory changes which make ricottas unacceptable for consumers' consumption. For that reason, the presence of some pathogenic bacteria as Listeria monocytogenes, Bacillus cereus and Salmonella spp. was not investigated: moreover, all the previous analyses done on this type of ricottas testified that their concentration was equal to zero.

Therefore, analyses searched for lactic acid bacteria (LAB) that are a group of gram-positive bacteria responsible of spoilage under low oxygen, low temperature and acidic conditions: their undesirable changes in milk and derivatives are off-flavours, gas formation in cheeses (blowing) and acidification (Rawat 2015). Moreover, the presence of negative nuclease cocci and Enterobacteria was investigated because they could be an index of non-hygienic production process. Finally, the total bacteria count was analyzed taking account of all types of bacteria that grew up in ricottas.

Analyses were conducted at illustrated times (Figure 1) with the same method: approximately $20 \mathrm{~g}$ of ricotta in each tray were diluted with 9 parts of citrate buffer (trisodium citrate 20g/L) and homogenized with Stomacher for 120 seconds. Then, the suspension was used for serial dilutions in physiological solution $(\mathrm{NaCl}$ 9g/L) inoculated in Petri dishes in order to search for microbial groups.

Finally, Crison $\mathrm{pH}$-meter was used to measure the $\mathrm{pH}$ of each samples in order to take account of possible acidifications that occurred in ricottas.
Table 1: Analyses parameters and culture medium

\begin{tabular}{|c|c|c|}
\hline Culture medium & $\begin{array}{c}\text { Microbial } \\
\text { group }\end{array}$ & Parameters \\
\hline $\begin{array}{c}\text { Violet red Bile } \\
\text { Glucose Agar } \\
\text { (VRBGA) }\end{array}$ & Enterobacteria & $37^{\circ} \mathrm{C}, 48 \mathrm{~h}$ \\
\hline $\begin{array}{c}\text { Plate count Agar } \\
\text { (PCA) }\end{array}$ & $\begin{array}{c}\text { Total bacterial } \\
\text { count }\end{array}$ & $30^{\circ} \mathrm{C}, 72 \mathrm{~h}$ \\
\hline $\begin{array}{c}\text { Negative } \\
\text { Baird \& Parker Agar }\end{array}$ & $\begin{array}{c}\text { nuclease cocci } \\
\text { Yeast Peptone } 72 \mathrm{~h}\end{array}$ \\
\hline $\begin{array}{c}\text { Yeasts and } \\
\text { molds }\end{array}$ & $28^{\circ} \mathrm{C}, 5$ days \\
\hline Dextrose Agar (YPD) & $\begin{array}{c}\text { Lactic acid } \\
\text { bacteria }\end{array}$ & $\begin{array}{c}30^{\circ} \mathrm{C}, \\
\text { Mnaerobic, } \\
5 \text { days }\end{array}$ \\
\hline
\end{tabular}

\subsection{Microbial growth curve}

Microbial growth in foods could be compared to a batch culture in a growth medium, where nutrients are exhausted while metabolites are accumulated and could inhibit the cells growth. In this ecosystem, microbial growth is characterized by different phases:

1- Lag phase. Firstly, bacteria have to adapt to growth conditions: they start to synthetize enzymes and intermediate metabolites, but are not able to divide. The duration of this phase depends on the type of bacteria and environmental factors such as $\mathrm{CO}_{2}$, temperature or $\mathrm{pH}$.

2- Log or exponential phase. Cells start to reproduce into two daughter cells and their number increase exponentially. In the chart, a straight line represents this period: the slope is the specific growth rate of the organism, which is a measure of the number of division per cell per unit time.

3- Stationary phase. The growth and cell division cease due to exhaustion of nutrients, accumulation of toxic products or in general a growth-limiting factor. The phase is represented by a straight horizontal line. Growth rate and death rate are equal.

4- Decline or death phase. The total number of cells remains constant, but the number of viable cells gradually decreases due to lack of nutrients or other injurious conditions.

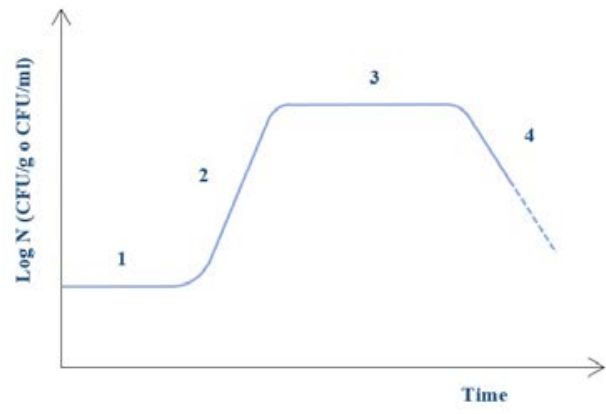

Figure 2: Microbial Growth Curve

\subsection{Microbial growth models}

In order to secure food safety, predictive microbiology creates models to predict microbial growth and inactivation in food products. In particular, primary models describes kinetics of growth, inactivation or 
survival. Secondary models study the effects of environmental and process conditions of primary models parameters. Finally, mathematical expressions are collected into different software, called tertiary models, useful for researchers who want to study microbial growth in foods: ComBase Predictor and Pathogen Modeling Program are the most famous and used.

There is a large number of empirical sigmoidal equations of primary models: they are indispensable tools for the comprehension, prevision and control of phenomena caused by the growth of microorganisms, as food deterioration, pathogenic growth and metabolite production. The modelling purpose is the individuation of a mathematical expression able to predict the growth in every instant of time and estimate the most important parameters in every growth curve, as the lag phase duration $(\lambda)$ and the maximum specific growth rate $\left(\mu_{\max }\right)$. In particular, in order to create a safe food characterized by a long shelf life, the growth inhibition of pathogenic and spoilage microorganisms is desired: it means to prolong $\lambda$ and reduce $\mu_{\max }$.

The Gompertz primary model is a sigmodal curve where the lag phase is calculated from a geometrical interpretation: it was often used in order to describe the microbial multiplication until the 90s. However, in 1994 Baranyi and Roberts studied a new mathematical approach for a mechanical model for the lag phase (Baranyi and Roberts 1994). Their model is the most widely used, because it can apply various environmental factors appropriately and interpret the calculated parameters biologically. The Baranyi equation is the following:

$$
\begin{gathered}
y(t)=y_{0}+\mu_{\max } A(t)-\ln \left(1+\frac{e^{\mu_{\max } A(t)}+1}{e^{\left(y_{\max }-y_{0}\right)}}\right) \\
A(t)=t+\frac{\ln \left(e^{-\mu_{\max t}}+e^{-h_{0}}-e^{-t-h_{0}}\right)}{\mu_{\max }}
\end{gathered}
$$

In the model, $y_{0}$ is the initial bacterial counts, while $y_{\max }$ is the final bacterial counts.

In the equation (2) $\mathrm{h}_{0}$ is called "work to be done": it's the work needed by the cell for the adaptation and the duplication. It could be expressed also by $\alpha_{0}$ parameter, that is the "initial physiological state": it's equal to zero if cells don't duplicate (infinite lag phase), or $\alpha_{0}=1$ if all cells reproduce immediately $(\lambda=0)$. The expression of these parameters is reported in the following equations:

$$
\begin{aligned}
& h_{0}=\lambda \mu_{\max }=\ln \left(1+\frac{1}{q_{0}}\right)=-\ln \alpha_{0} \\
& \alpha_{0}=e^{-\mu_{\max } \lambda}
\end{aligned}
$$

To model microbiological data during the observation period, ComBase Predictor is used. It is possible to use it online or with the DMfit program provided for Excel. The program reports the estimated equation parameters and the coefficient of determination $\left(\mathrm{R}^{2}\right)$ and Squared Error (SE), which indicate the statistical fit of the primary model.

\section{RESULTS AND DISCUSSION}

3.1 Visible changes during observation

At T0, the main visible effect of the treatment is syneresis that is the separation of the aqueous phase of ricotta, due to the pressure. At T1, untreated ricottas started to change color: they become light-rose and trays started to swell up. The Oxybaby instrument, able to measure the percentages of gas inside each tray, showed that in bulgy packaging the Oxygen was completely consumed and Carbon Dioxide was produced: it was a clear index of fermentation in untreated ricottas. Contrariwise, HPP ricottas remained white and without visible change for 30 days.

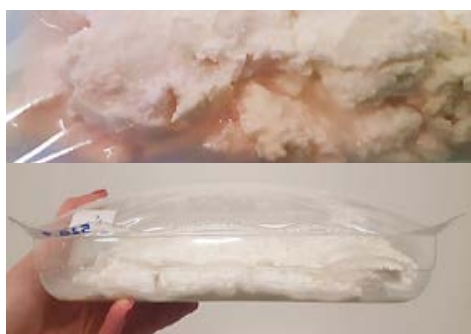

Figure 3: Rose untreated ricottas and bulgy trays

\subsection{Microbiological analyses results}

Results show that, at the beginning of the observation, $\mathrm{pH}$ is very similar between untreated and HPP trays, but after 10 days, untreated ricottas acidified. Instead, acidification in ricottas treated at $600 \mathrm{MPa}$ for 5 minutes started only after 30 days in the fridge at $4^{\circ} \mathrm{C}$. Certainly, the result demonstrates the ability of high pressure to slow down chemical changes and reactions in foods.

Table 2: $\mathrm{pH}$ results

\begin{tabular}{|c|c|c|}
\hline Time & Untreated & HPP \\
\hline T0 & 5.15 & 5.13 \\
\hline T1 & 4.66 & 5.09 \\
\hline T2 & 5.74 & 5.10 \\
\hline T3 & 4.50 & 4.72 \\
\hline
\end{tabular}

Microbiological results show that at $\mathrm{T} 1$ in untreated ricottas some microorganisms as negative nuclease cocci, yeast, molds and lactic acid bacteria started to grow up: of course the last one were the main cause of the acidification, fermentation and swelling. Instead, microbial growth in HPP ricottas started to be significant only after 30 days of refrigerated storage. Enterobacteria didn't grow up at any time in any ricottas ( $<10 \mathrm{CFU} / \mathrm{g})$.

Table 3: Total bacterial count results [CFU/g]

\begin{tabular}{|c|c|c|}
\hline Time & Untreated & HPP \\
\hline T0 & 2.000 & 2.500 \\
\hline T1 & 1.600 .000 & 4.000 \\
\hline T2 & 272.000 .000 & 240.000 \\
\hline T3 & 490.000 .000 & 13.200 .000 \\
\hline
\end{tabular}

Table 4: Negative nuclease cocci results [CFU/g] 


\begin{tabular}{|c|c|c|}
\hline Time & Untreated & HPP \\
\hline T0 & $<10$ & $<10$ \\
\hline T1 & 1.040 & 80 \\
\hline T2 & 300.000 & 240 \\
\hline T3 & 600.000 & 380 \\
\hline
\end{tabular}

Table 5: Yeasts and molds results [CFU/g]

\begin{tabular}{|c|c|c|}
\hline Time & Untreated & HPP \\
\hline T0 & $<100$ & $<100$ \\
\hline T1 & 400 & 1.000 \\
\hline T2 & 3.500 & 800 \\
\hline T3 & 4.500 & 1.200 \\
\hline
\end{tabular}

Table 6: Lactic acid bacteria results [CFU/g]

\begin{tabular}{|c|c|c|}
\hline Time & Untreated & HPP \\
\hline T0 & $<10$ & $<10$ \\
\hline T1 & 5.400 .000 & 5.000 \\
\hline T2 & 45.000 .000 & 43.000 \\
\hline T3 & 50.000 .000 & 12.000 \\
\hline
\end{tabular}

In microbiology, in order to calculate the magnitude of the change in cell number, a logarithmic scale is often used. In fact, taking the log value of a large number transforms it into a smaller one that is easier to work with. Therefore, the number of cells CFU/g were transformed in log: the charts show the different bacterial growth in treated and untreated ricottas during a month.

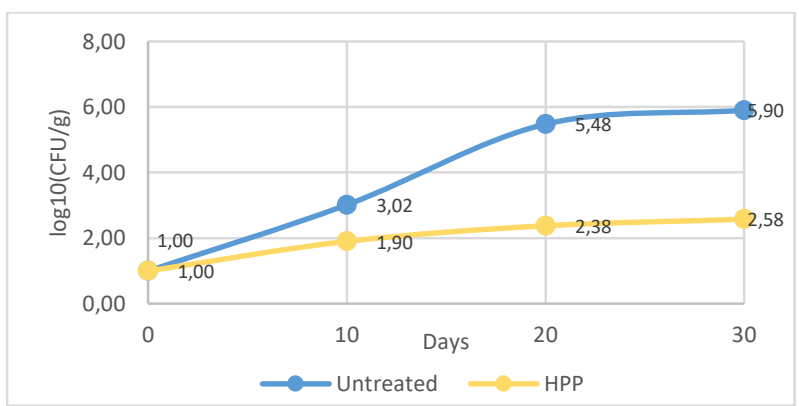

Figure 4: Nuclease negative cocci growth curve

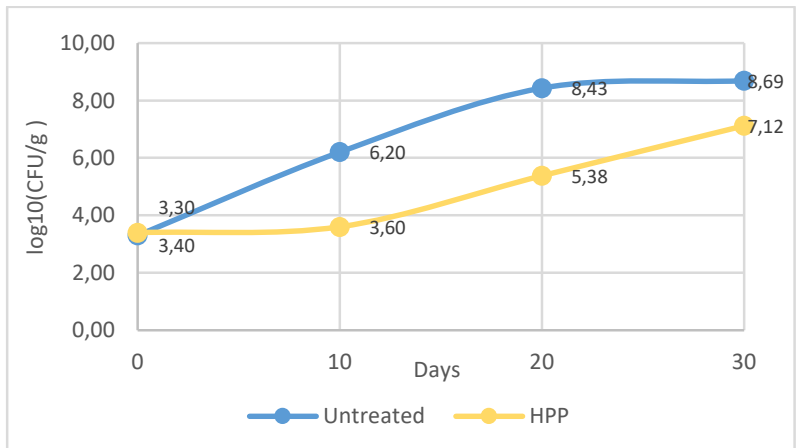

Figure 5: Total bacterial count growth curve

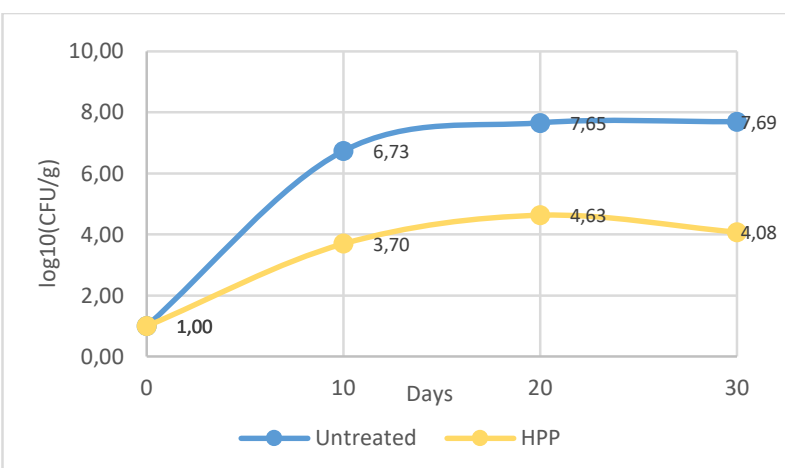

Figure 6: Lactic acid bacteria growth curve

Charts show that the microbial growth in HPP and untreated ricottas is very different. The untreated ricottas curves are similar to the exponential phase of the generic microbial growth illustrated in figure 2: it seems that, at $\mathrm{T} 0$, there are already the conditions of duplication of bacteria, who start to grow up quickly. Instead, the first section of HPP ricottas curves seems similar to the lag phase: cells need time to adapt to the new conditions of growth.

Especially, plots shows that the main difference between the two types of ricottas is the growth during time: in HPP ricottas is slower. In fact, using the following mathematical expression for each microorganisms at each observation time, it is possible to see that HPP inhibits bacterial growth from 1 to 3 log after 10 days, and up to $3 \log$ after 20 days.

$\log$ reduction $=\log \left(H P P_{(T i)}\right)-\log \left(\right.$ untreated $\left._{\left(T_{i}\right)}\right)$

In particular, looking at the curves, High Pressure seems able to prolong $\lambda$ and reduce $y_{\max }$ and $\mu_{\max }$ of acid lactic bacteria, negative nuclease cocci and total bacteria count. In other words, it means that HPP changes growth conditions in ricottas and does not allow cells to quickly reproduce. This is a very important result because prolonging the lag phase, the concentration of bacteria is lower and the food is safe for more time.

The content of acid lactic bacteria in untreated ricottas grows exponentially during time and after 20 days it's already greater than $10^{7} \mathrm{CFU} / \mathrm{g}$, showing an evident product's alteration. Instead, in HPP trays the number is lower, remaining less than $10^{5} \mathrm{CFU} / \mathrm{g}$ also after 30 days, testifying the safety of ricottas. The total bacterial count at T2 is greater than $10^{8} \mathrm{CFU} / \mathrm{g}$ in untreated ricottas, while in HPP ricottas is yet acceptable $\left(10^{5} \mathrm{CFU} / \mathrm{g}\right)$. Finally, yeast and molds concentration's limits are more respected in treated ricottas than in untreated ones.

Using ComBase Predictor online, the microbial growth curves were fitted with the most appropriate primary model among linear model, Baranyi and Roberts model and Biphasic model. On $y$-axis the concentration expressed in log CFU/g is reported, and on $\mathrm{x}$-axis time is expressed in hours. In the chart, data points represent the analyses results, while the curves are the model created by the software. 
In order to measure the adequacy of the model to describe data, the coefficient of determination $\mathrm{R}^{2}$ was calculated: the higher is $(\cong 1)$, the better is the adequacy.

$R^{2}=1-\frac{\sum(y-\hat{y})^{2}}{\sum(y-\bar{y})^{2}}$

The microorganisms' growth in treated ricottas can be modelled with the equation of Baranyi and Roberts.

In particular, the content of acid lactic bacteria can be modelled with the equation of Baranyi and Roberts without the lag phase $\left(\mathrm{R}^{2}=0,942\right.$ and $\mathrm{SE}$ of fit $\left.=0,389\right)$. The essential parameters that can describe the curve are the maximum growth rate $\mu_{\max }$, the initial value $y_{0}$ and the final value $y_{\max }$ (Table 7).

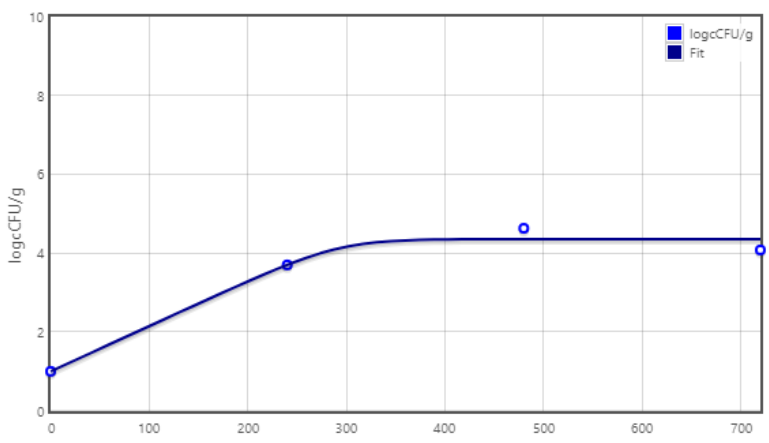

Figure 7: Lactic acid bacteria in HPP ricottas modelled with Baranyi and Roberts equation without lag phase

Total bacteria count can be represented by the same model but with no asymptote. $\mathrm{R}^{2}$ value is very high $(0,995)$ and $\mathrm{SE}$ of fit is 0,127 . The maximum growth rate, the lag/shoulder parameter and the initial value are reported in table 7 .

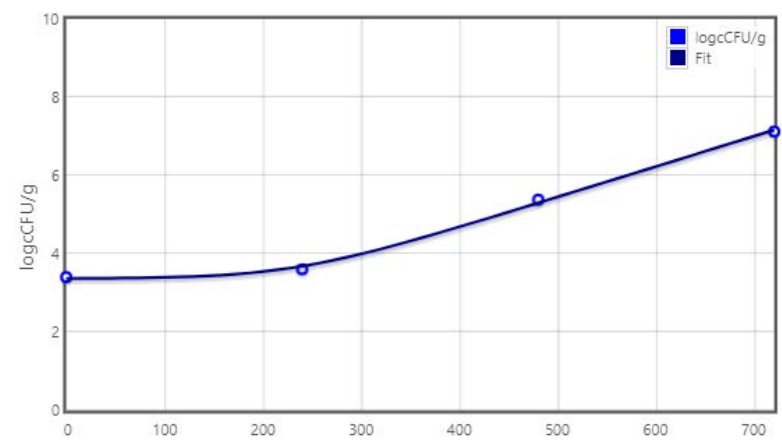

Figure 8: Total bacteria count in HPP ricottas modelled with Baranyi and Roberts equation without asymptote

Finally, also the content of negative nuclease cocci in HPP ricottas can be represented with Baranyi and Roberts model without lag phase, with $\mathrm{R}^{2}=0,968$ and SE of fit $=0,126$.

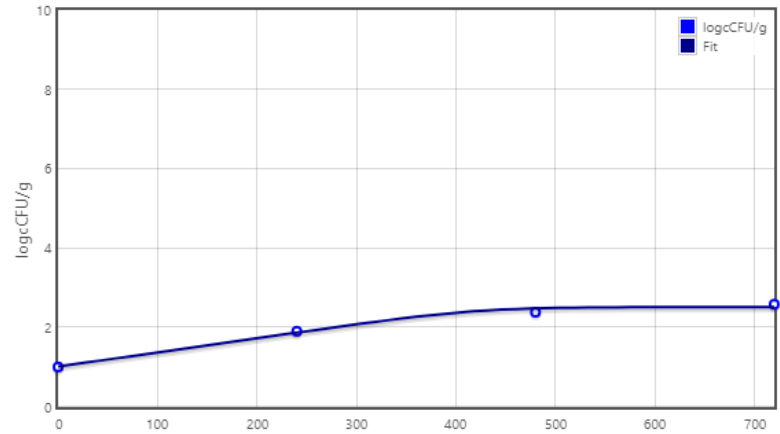

Figure 9: Negative nuclease cocci in HPP trays modelled with Baranyi and Roberts (no lag phase)

Table 7: Growth parameters in HPP ricottas

\begin{tabular}{|c|c|c|c|c|}
\hline $\begin{array}{c}\text { Baranyi- } \\
\text { Roberts }\end{array}$ & $\boldsymbol{y}_{\mathbf{0}}$ & $\boldsymbol{y}_{\max }$ & $\boldsymbol{\mu}_{\max }$ & $\boldsymbol{\lambda}$ \\
\hline $\begin{array}{c}\text { Acid } \\
\text { lactic } \\
\text { bacteria }\end{array}$ & $\begin{array}{c}1,0000555 \\
\pm 0,389\end{array}$ & $\begin{array}{c}4,355 \\
\pm 0,276\end{array}$ & $\begin{array}{c}0,0115 \\
\pm 0,00261\end{array}$ & $/$ \\
\hline $\begin{array}{c}\text { Total } \\
\text { bacterial } \\
\text { count }\end{array}$ & $\begin{array}{c}3,364 \\
\pm 0,122\end{array}$ & $/$ & $\begin{array}{c}0,00779 \\
\pm 0,000543\end{array}$ & $\begin{array}{c}232,459 \\
\pm 34,152\end{array}$ \\
\hline $\begin{array}{c}\text { Nuclease } \\
\text { negative } \\
\text { cocci }\end{array}$ & $\begin{array}{c}1,00906 \\
\pm 0,126\end{array}$ & $\begin{array}{c}2,51 \\
\pm 0,102\end{array}$ & $\begin{array}{c}0,00358 \\
\pm 0,000735\end{array}$ & $/$ \\
\hline
\end{tabular}

Finally, each microorganism's growth in untreated ricottas was modelled with ComBase using the Baranyi and Roberts Model without lag phase. Parameters are reported in the following table and charts are attached in appendix.

Table 8: Growth parameters in untreated ricottas

\begin{tabular}{|c|c|c|c|c|c|}
\hline $\begin{array}{c}\text { Baranyi- } \\
\text { Roberts }\end{array}$ & $\boldsymbol{y}_{\mathbf{0}}$ & $\boldsymbol{\mu}_{\max }$ & $\boldsymbol{y}_{\max }$ & $\mathbf{R}^{2}$ & $\mathbf{S E}$ \\
\hline $\begin{array}{c}\text { Lactic } \\
\text { Acid } \\
\text { bacteria }\end{array}$ & $\begin{array}{c}1 \\
\pm 0,0281\end{array}$ & $\begin{array}{c}0,0247 \\
\pm 0,000208\end{array}$ & $\begin{array}{c}7,67 \\
\pm 0,0199\end{array}$ & 1 & 0,0281 \\
\hline $\begin{array}{c}\text { Total } \\
\text { bacterial } \\
\text { count }\end{array}$ & $\begin{array}{c}3,305 \\
\pm 0,042\end{array}$ & $\begin{array}{c}0,012 \\
\pm 0,000233\end{array}$ & $\begin{array}{c}8,67 \\
\pm 0,0375\end{array}$ & 1 & 0,0423 \\
\hline $\begin{array}{c}\text { Nuclease } \\
\text { negative } \\
\text { cocci }\end{array}$ & $\begin{array}{c}0,921 \\
\pm 0,266\end{array}$ & $\begin{array}{c}0,00959 \\
\pm 0,00116\end{array}$ & $\begin{array}{c}5,826 \\
\pm 0,281\end{array}$ & 0,985 & 0,277 \\
\hline
\end{tabular}

Parameters' results confirm that the microbial growth in HPP ricottas is lower than in untreated ones. Considering the total bacteria count, the treatment prologs the lag phase, while in the others type of ricotta this phase is absent and cells start to reproduce immediately. Finally, as seen before, $y_{\max }$ of each microorganism is higher in untreated ricottas, testifying greater deterioration's reactions. Since HPP ricottas at T3 respect all the limits of bacterial count permitted, it means that the treatment can ensure to this product a shelf life up to 30 days, more than the double guaranteed by untreated ones. 


\section{CONCLUSIONS}

Food industry priorities in the Parmigiano Reggiano area are the creation of safe, nutritious and tasty dairy products with a long shelf life. For that reason, the High Pressure Processing (600 MPa, $5 \mathrm{~min}$ ) was tested on ricottas, which were observed for a month in refrigerated storage at $4^{\circ} \mathrm{C}$ and compared with the same number of untreated ricottas. Observation and microbiological analyses show that HPP is able to slow down chemical reactions in treated ricottas, preserving their color and inhibiting the microbial growth up to $3 \mathrm{log} \mathrm{CFU} / \mathrm{g}$. In fact, modelling the total bacteria count and lactic acid bacteria growth in HPP ricottas with the Baranyi and Roberts primary model, it can be seen that the treatment prolongs the lag phase $\lambda$ and reduce the maximum growth rate $\mu_{\max }$ compared to untreated ricottas modelled with Baranyi and Roberts model without lag phase. Thanks to this, HPP ricottas have a shelf life of 30 days, while the untreated ones after 10 days of storage are already not suitable for consumers. However, it could be interesting to study the influence of pressure on microbial growth, analyzing different treatment parameters (as 400, 500 and $600 \mathrm{Mpa}$ ): of course, it will be the object of study in future developments of this work.

\section{ACKNOWLEDGMENTS}

Initiative under the Regional Rural Development Program 2014-2020 - Type of operation 16.1.01 Operations of the European Partnership for Innovation: "Productivity and sustainability of agriculture" - Focus Area 2A - Project "Milk beef in the Parmigiano Reggiano area: innovation and tradition for sustainable breeding and quality products”.

The authors thank also HPP Italia Srl and Michele Morbarigazzi for the possibility of using their HPP equipment.

\section{APPENDIX}

Figure 10: Lactic Acid bacteria in untreated ricottas modelled with Baranyi and Roberts equation (no lag)

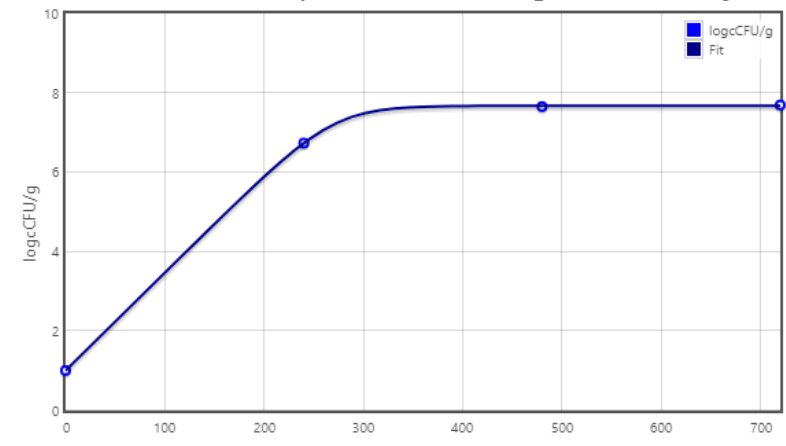

Figure 11: Nuclease negative cocci in untreated ricottas modelled with Baranyi and Roberts equation (no lag)

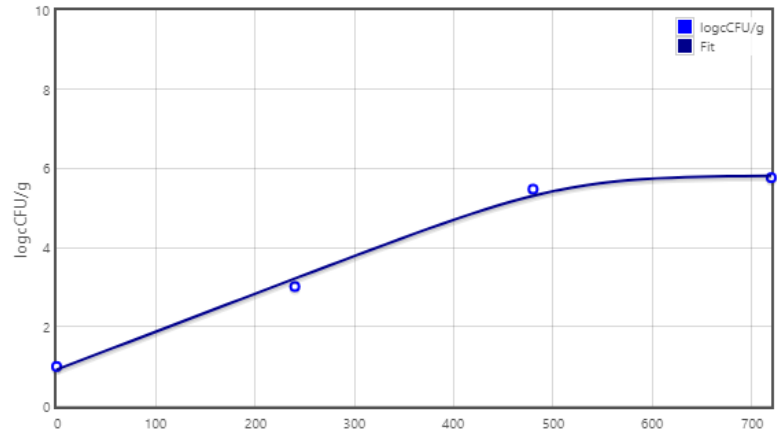

Figure 12: Total bacteria count in untreated ricottas modelled with Baranyi and Roberts equation (no lag)

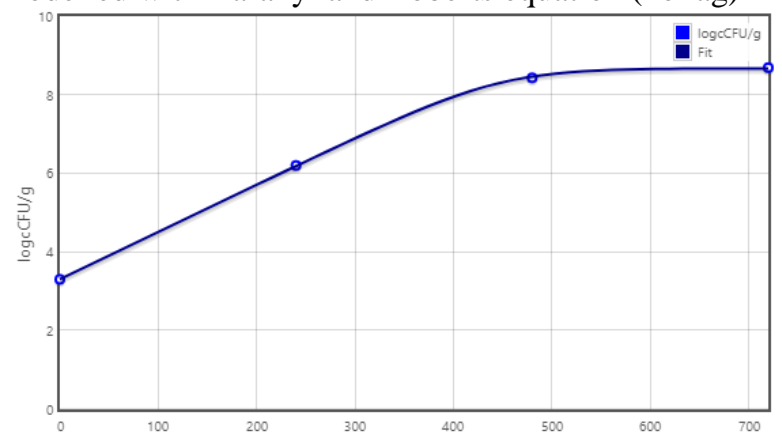

REFERENCES

Balasubramaniam V.M., Martinez-Monteagudo Sergio I., Gupta R., 2015. Annual Review of Food Science and Technology, 435-460.

Baranyi J., Roberts T.A., 1994. A dynamic approach to predicting bacterial growth in food. International Journal of Food Microbiology, 23, 277-294

Bertolini M, Bottani E, Vignali G, Volpi A., 2016 Comparative life cycle assessment of packaging systems for extended shelf life milk, Packaging Technology and Science 29 (10), 525-546.

Calzada J., del Olmo A., Picon A., Nunez M., 2015. Effect of High Pressure Processing on the Lipolysis, Volatile Compunds, Odour and Colour of Cheese Made from Unpasteurized Milk. Food Bioprocess Technol, 8, 10776-1088.

Chen H., Hoover G.Dallas, 2003. Modeling the combined effect of high hydrostatic pressure and mild heat on the inactivation kinetics of Listeria Monocytogenes Scott A in whole milk. Innovative Food Science and Emerging Technologies, 4, 2534.

Datta N., Deeth H.C., 1999. High pressure processing of milk and dairy products. Australian Journal of Dairy Technology, Vol 54, 41-48.

Devi A.F., Buckow R., Hemar Y., Kasapis S., 2013. Structuring dairy systems through high processing. Journal of Food Engineering, 114, 106-122.

Elamin W.M., Endan J.B, Yosuf Y.A., Shamsudin R., Ahmedov A., 2015. High Pressure Technology and Equipment Evolution: A Review. Journal of Engineering Science and Technology Review, 8 (5), 75-83 
FCD2009,

http://www.fcd.fr/media/filer_public/7e/51/7e5126

1b-e18d-4c9f-be28-

5dad72e4cfd0/1200_fcd_criteres_microbiologique s_2016_ateliers_rayons_coupe_28012016.pdf

Giacometti F., Bardasi L., Merialdi G., Morbarigazzi M., Federici S., Piva S., Serraino A., 2016. Shelf life of donkey milk subjected to different treatment and storage conditions. American Diary Science Association, 4291-4299.

Gutiérrez L.F., 2016. Conjugated linoleic acid in milk and fermented milks: variation and effects of the technological processes. Vitae, revista de la facultad de ciencia farmacéuticas y alimentarias, 23 (2), 134-145

HPP Machine QFP350L by Avure Technologies, http://www.chiefup.com.tw/data/high_pressure/qfp 3501-eu-may-2007.pdf

IL PRA EasyForm Machine, https://ilpra.com/wpcontent/uploads/2018/06/Depliant-Easyform-F0ITA_ENG_FRA_SPA.pdf

Lambert Y., Demazeau G., Largetau A., Bouvier J.M., Laborde-Croubit S., Cabannes M., 2000. Packaging for High-pressure Treatments in the Food Industry. Packaging Technology and Science, 13, 63-71.

Mosna D., Vignali G., 2015. Three-dimensional CFD simulation of a "steam water spray" retort process for food vegetable products, International journal of food engineering 11 (6), 715-729

Mussa D.M., Ramaswamy H.S., Smith J.P., 1998. HighPressure Destrucion Kinetics of Listeria Monocytogenes on Pork. Journal of Food Protection. 62 (1), 40-45.

Okpala C.O.R., Pigott J.R., Schaschke C.J., 2009. Effect of high-pressure processing (HPP) on the micrioblogical, physco-chemical and sensory properties of fresh cheeses: A reviw. African Journal of Biotechnology, 8 (25), 7391-7398).

Pala C., Scarano C., Venusti M., Sardo D., Casti D., Cossu F., Lamon S., Spanu V., Ibba M., Marras M., Paba A., Spanu C., De Santis E.P.L., 2016. Shelf life evaluation of ricotta fresca sheep cheese in modifed atmosphere packaging. Italian Journal of Food Safety, 5:5502, 134-139.

Pega J., Denoya G.I., Castells M.L., Sarquis S., Aranibar G.F., Vaudagna S.R., Nanni M., 2018. Effect of High-Pressure Processing on Quality and Microbiological Properties of a Fermented Beverage Manufactured from Sweet Whey Throughout Refrigerated Storage. Food and Bioprocess Technology, 11, 1101-1110.

Rawat S., 2015, Food Spoilage: Microorganisms and their prevention., Asian Journal of Plant Science and Research, 5(4), 47-56.

Serment-Moreno V., Fuentes C., Barbosa.Cànovas G., Torres J.A., Welti-Chanes J., 2015. Evaluation of High Pressure Processing Kinetics Models for Microbial Inactivation Using Standard Statistical Tools and Information Theory Criteria and the Development of Generic Time-Pressure Functions of Process Design. Food Bioprocess Technol, 8, 1244-1257.

Serment-Moreno V., Franco-Vega A., EscobedoAvellaneda Z., Fuentes C., Torres J. A., DibildoxAlvarado E., Welti-Chanes J., 2017. The logisticexponential Weibull model as a tool to predict natural microflora inactivation of agave mapsiaga aguameil (agave sap) by high pressure tratments. Journal of Food Processing and Preservation, 1-9.

Ribeiro L.R., De Castro L.J.B.R., Cristianini M., 2018. Effect of high-pressure processing on the characteristics of cheese made from ultrafiltered milk: influence of the kind of rennet. Innovative Food Science and Emerging Technologies, 50, 57 65.

Ugolotti S., Vignali G., 2018. International Food Operations and Processing Simulation Workshop, FoodOPS, 48-54.

Wibowo S., Essel E.A., De Man S., Bernaert N., Droogenbroeck B.V., Grauwet, Loey V.A., Hendrickx M., 2019. Comparing the impact of high pressure, pulsed electric field and thermal pasteurization on quality attributes of cloudy apple juice using targeted and untargeted analyses. Innovative Food Science and Emerging Technologies, 54, 64-77.

\begin{abstract}
AUTHORS BIOGRAPHY
Roberta STEFANINI is a scholarship holder at CIPACK research packaging center at the University of Parma. In March 2019, she achieved a master degree in Engineering for Plants and Machines of Food Industry at the same university. Her main fields of research concern food packaging and processing.
\end{abstract}

Giuseppe VIGNALI is an Associate Professor at University of Parma. He graduated in 2004 in Mechanical Engineering at the University of Parma. In 2009, he received his $\mathrm{PhD}$ in Industrial Engineering at the same university, related to the analysis and optimization of food processes. His research activities concern food processing and packaging issues and safety/security of industrial plant. Results of his studies related to the above topics have been published in more than 100 scientific papers, some of which appear in national and international journals and conferences.

Fabio COLORETTI is a fixed-term contract worker at Alma Mater Studiorum University of Bologna at Agricultural and Food Science Department. He graduated in 2000 in Agricultural Science and he received a PhD in Food Biotechnology in 2004. His themes of research concern food microbiology, especially wine, dairy and fermented meat microbiology. $\mathrm{He}$ is author of about 50 scientific papers and co-author of three technical books. 


\title{
LIFE CYCLE ASSESSMENT OF ORGANIC PARMESAN CHEESE CONSIDERING THE WHOLE DAIRY SUPPLY CHAIN
}

\author{
Giulia Borghesi $^{(a)}$, Giuseppe Vignali ${ }^{(b)}$ \\ (a) Cipack Centre, University of Parma, Parco Area delle Scienze, 43124 Parma (Italy) \\ (b) Department of Engineering and Architecture, University of Parma, Parco Area delle Scienze, 181/A, 43124 Parma
}

(Italy)

(a)giulia.borghesi@studenti.unipr.it ${ }^{(b)}$ giuseppe.vignali@unipr.it

\begin{abstract}
Agriculture and food manufacturing have a considerable effect on the environment emissions: holdings and farms play an important role about greenhouse gas emissions and water consumption. This study aims at evaluating the environmental impact of one of the most important Italian DOP product: organic Parmesan Cheese. Environmental performances of the whole dairy supply chain have been assessed according to the life cycle assessment approach (LCA).

In this analysis Parmesan Cheese is made from an organic dairy farm in Emilia Romagna, which uses the milk from three different organic livestock productions. Organic agriculture is different from conventional; the major difference is represented by the avoidance of the use of synthetic fertilizers and pesticides made in chemical industry process. Organic agriculture uses organic fertilizers to encourage the natural fertility of the soil respecting the environment and the agro-system. In this case, life cycle approach is used to assess the carbon footprint and the water footprint of organic Parmesan Cheese considering the milk and cheese production. The object at this level is investigating the environmental impact considering the situation before some improvement changes.

The functional unit is represented by $1 \mathrm{~kg}$ of organic Parmesan Cheese; inventory data refer to the situation in year 2017 and system boundaries consider the inputs related to the cattle and dairy farm until the ripening (included).

The carbon footprint is investigated using IPCC 2013 Global Warming Potential (GWP) 100a method, developed by Intergovernmental Panel on Climate Change, and reported in $\mathrm{kg}$ of CO2eq. Otherwise, water footprint allows to measure the water consumption and in this work it is assessed using AWARE method (Available Water REmaining).
\end{abstract}

Keywords: Life Cycle Assessment (LCA), organic Parmesan Cheese, Carbon footprint, Water footprint.

\section{INTRODUCTION}

In recent years, the global food system has proved to be unsustainable (Mancini et al., 2019). Overall in this sector there is a need for a general sustainable development, being producers and consumers looking for reaching both environmental, economic and social sustainability (Mancini et al., 2019).

Parmesan Cheese is one of the most important Italian DOP product and its manufacturing is strictly controlled by its consortium. This consortium has also the task of draw up the regulations and its experts examine all the wheels before declaring the DOP certification. The production of Parmesan cheese is authorized only in a specific area, which included the provinces of Reggio Emilia, Parma, Modena and parts of the provinces of Bologna and Mantua.

Life cycle assessment is a method of identifying the environmental impact of a product or service by analyzing all associated inputs and outputs, based on system boundaries. The method is divided into: goal and scope, inventory, impacts and interpretation of results (Uctug, 2019).

The dairy sector is a very impactful activity, in particular as far as the milk production is concerned (Bava et al., 2018). Several publications have been done on this sector to analyze several products obtained by cow milk, showing how the ripening phase (Sanjuan et al., 2011), the packaging (Manfredi et al., 2015; Bertolini et al., 2016,) and the needs of refrigeration (van Middelaar et al.,2011) play a crucial aspect in defining the environmental impact.

Based on these premises, the aim of this study is carried out the impact assessment of a wheel of parmesan Cheese manufactured in a farm before some improvements planned to reduce greenhouse gas emissions and water consumption. Some planned improvements are, for example, the inserting of photovoltaic panels, the modernization of machines and the introduction of a new concentration plant for whey, which allows to reduce the number of truck trips for disposal.

\section{METHODOLOGY}

\subsection{Life Cycle Assessment (LCA)}

This study is based on an attributional LCA analysis, in accordance with ISO 14040 (2006) and ISO 14044 (2006), using software SimaPro 8.5.2.0 (PRé 
Consultants). Ecoinvent and Agri-footprint and Methods have been used as secondary data database, when primary data have been not available. Carbon footprint and water footprint have been considered as impact categories in this study.

The carbon footprint is investigated using IPCC 2013 Global Warming Potential (GWP) 100a method, developed by Intergovernmental Panel on Climate Change, and reported in $\mathrm{kg}$ of CO2eq. Otherwise, water footprint allows to measure the water consumption and in this work it is assessed using AWARE method (Available Water REmaining).

\subsection{Goal and scope}

This study is carried out to assess the environmental impact of organic Parmesan Cheese, in particular investigating the carbon footprint and the water footprint considering first the milk and then the cheese production. Three different organic breedings of bovine produce the milk, which is then transported to the dairy factory and used to produce cheese. Inside the dairy farm several phases are need to obtain the Parmesan Cheese (as reported in Figure 1).

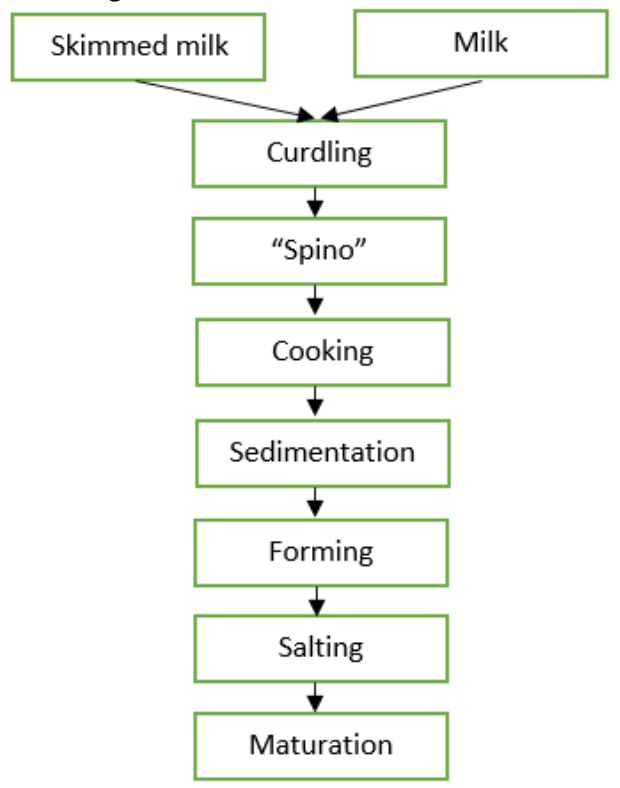

Figure 1: Parmesan cheese process

The considered dairy farm is located in Emilia Romagna (Italy); every day the evening cow milk is left to rest in large vats until morning of the day after to obtain the separation of the fattiest part. When the milk of the morning arrives from the three farms, this is added to the milk of the evening before and the blend is poured into bell-shaped copper cauldrons.

The next step is starting heating and adding to this blend the calf rennet and the whey obtained the day before. This mixture coagulates and produces the curd, which is broken into small granules using the "spino" tool. Then the cooking process starts and curd is heated to $55^{\circ} \mathrm{C}$ to obtain a single compact mass.
After about one-hour the cheese maker removes the cheese mass, which is then cut in two identical parts. Cheese wheels are wrapped in typical linens and placed in moulds to give the final shape.

Each cheese wheel has a unique number of identification. Some marking bands are used to mark the month, the year of production and the registration number around the circumference of cheese wheel. Then the cheese is immersed for few days in a solution saturated with salt. The final step is the ripening in maturation rooms.

The fattiest part of the milk is used to produce an organic butter, but this production process does not take place in this dairy farm.

\subsection{Functional unit}

In a LCA study, the functional unit (FU) is the reference for input and output data to quantify the performance of a product system (ISO 14040, 2006).

In this study functional unit is $1 \mathrm{~kg}$ of organic Parmesan cheese. For each farm the unit of $1 \mathrm{~kg}$ of Fat and Protein Corrected Milk has been recreated, as suggested by IDF (2015):

$$
\begin{aligned}
\operatorname{FPCM}\left(\frac{k g}{y r}\right)= & \text { Production }\left(\frac{k g}{y r}\right) *[0.1226 \\
& * \text { fat } \%+0.0776 * \text { protein } \% \\
& +0.2534]
\end{aligned}
$$

The term "Production" is the amount of milk produced while the percentage of fat and protein is related to the chemical analysis of each bovine herd. The amount of Fat and Protein Corrected Milk is used to reproduce the functional unit.

\subsection{System boundaries}

Environmental impact assessment is carried out from the "cradle-to-dairy gate", considering the cattle farms and the cheese production until the ripening phase, while packaging, distribution, consumption and packaging end-of-life are excluded.

Each farm has been analyzed separately with the aim of reproducing the daily quantity of Fat Protein Corrected Milk; subsequently the milk is used as input in parmesan cheese production process.

System boundaries generally includes the following phases:

- Seeds;

- Transports;

- Diesel;

- Crops production;

- $\quad$ Purchased feeds;

- $\quad$ Process of sowing;

- Water consumption;

- Detergents;

- Natural gas;

- Energy consumption in breeding and cheese factory;

- FPCM production;

- Daily feeding of cattle;

- $\quad$ Livestock manure; 
- Whey;

- $\quad$ Treatment and disposal of whey;

- Rennet;

- Salt;

- $\quad$ Steam

Both the considered farms are organic, so livestock wastes are used as fertilizer; additionally, in two stables biogas plants have been already installed. The digestate, exiting by both the biogas systems, is used as organic fertilizer; both the plants produce also electricity.

Electricity produced from biogas is considered an energy from a renewable source and therefore it has a positive impact on the analysis, because it is demonstrated that biogas plant helps to reduce the environmental impact (Battini et al., 2014).

\subsection{Life cycle inventory analysis}

Inventory analysis consists of collecting input and output data to recreate the process units; the aim is to provide some objective data to allow their processing and evaluation in Life Cycle Impact Assessment and Life Cycle Interpretation phases (Baldo et al., 2008).

In each farm the daily amount of FPCM has been recreated, considering the feeding of cows, the consumption and emissions, as reported in Figure 2.

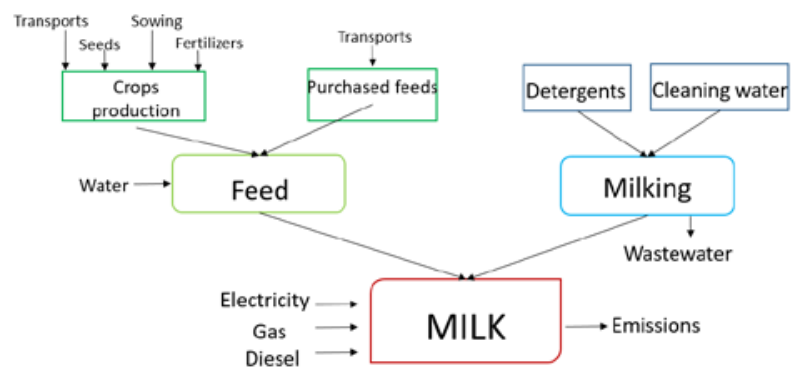

Figure 2: FPCM flow chart

The first two farms have only one stable each one. The third farm is instead composed by two sheds, so the values considered for the third farm have been obtained as the arithmetic mean of the two sheds.

The number of animals and the herd composition have been recorded on each farm, as shown in the table 1 .

Table 1: Primary data about number and herd composition

\begin{tabular}{|c|c|c|c|}
\hline & Farm 1 & Farm 2 & Farm 3 \\
\hline $\begin{array}{c}\text { Lactating } \\
\text { cows }\end{array}$ & 289 & 320 & 253 \\
\hline Dry cows & 70 & 75 & 80 \\
\hline Heifers & 310 & 275 & 203 \\
\hline
\end{tabular}

As cow's feeding is concerned, the production of fodder, cereals and the purchase of feed has been taken into account. Each forage and cereal has been reproduced considering seed, sowing and organic fertilizers.

The daily emissions (methane, nitrous oxide and ammonia) from animals and the farm operations have been calculated as an average of the data proposed by
Baldini (Baldini et al., 2018). Data have been reported in Table 2.

Table 2: Daily emissions of animal category expressed as kg of gas head ${ }^{-1}$

\begin{tabular}{|l|c|c|}
\hline & Lactating & Dry \\
\hline $\mathrm{CH}_{4}$ & 0,59 & 0,19 \\
\hline $\mathrm{N}_{2} \mathrm{O}$ & 0,003 & 0,01 \\
\hline $\mathrm{NH}_{3}$ & 0,11 & 0,09 \\
\hline
\end{tabular}

So environmental impact of FPCM production is included in the assessment of functional unit impact. All daily data related to cheese are collected in the dairy farm.

The input data are:

$\begin{array}{ll}\text { - } & \text { Milk (Fat Protein Corrected Milk) } \\ \text { - } & \text { Whey } \\ \text { - } & \text { Rennet } \\ \text { - } & \text { Energy } \\ \text { - } & \text { Natural gas } \\ \text { - } & \text { Water } \\ \text { - } & \text { Salt }\end{array}$

\subsection{Allocation}

Allocation is the breakdown between input and output flows of a process.

According to the ISO 14040, allocation between product and co-products should be avoided, but this is not always possible.

At farm level there are two products: milk and meat. So allocation is made according to IDF (2015):

$\mathrm{AF}=1-6,04 \mathrm{BMR}$

Where AF is the allocation factor for milk, and consequently (1 - AF) represents meat allocation factor. BMR is the ration between $M_{\text {meat }} / M_{\text {milk; }} M_{\text {meat }}$ is the quantity of the live weight of all animals sold and $\mathrm{M}_{\text {milk }}$ is the amount of milk sold, considered as the total quantity of FPCM.

Allocation factor for milk and meat has been calculate for each farm. Table 3 shows the percentages.

Table 3: Allocation factors between milk and meat

\begin{tabular}{|c|c|c|}
\hline & Milk (FPCM) & Meat \\
\hline Farm 1 & $81 \%$ & $19 \%$ \\
\hline Farm 2 & $77 \%$ & $23 \%$ \\
\hline Farm 3 & $82 \%$ & $18 \%$ \\
\hline
\end{tabular}

\section{RESULTS AND DISCUSSION}

\subsection{Impact assessment}

The aim is to estimate carbon footprint and water footprint of $1 \mathrm{~kg}$ of organic parmesan cheese. The impact categories considered are: climate change and water use. In the following section the results are presented separately for the two footprints. Carbon and water 
footprint have been calculated at first only for the milk and further for parmesan cheese.

\subsection{Carbon footprint}

The method to assess greenhouse gas emissions is IPCC, Intergovenmental Panel on Climate Change, which has only one impact category: climate change, measured in kg $\mathrm{CO}_{2}$ equivalent.

The environmental impact assessments of milk production, expressed for $\mathrm{kg}$ of FPCM are 1,33 kg $\mathrm{CO}_{2} \mathrm{eq}, 1,01 \mathrm{~kg} \mathrm{CO}$ eq and 1,1 $\mathrm{kg} \mathrm{CO}_{2} \mathrm{eq}$ for the three different farms. The results are aligned with values reported in other studies (Jayasundara et al., 2019; Baldini et al., 2018; Battini et al., 2016; Bacenetti et al., 2016).

These results are due, in particular, to emissions of animal and their daily feed.

Considering the materials and consumption to produce the functional unit of $1 \mathrm{~kg}$ Parmesan cheese, until ripening, the carbon footprint is $17,8 \mathrm{~kg} \mathrm{CO}_{2} \mathrm{eq}$. The most impactful category is milk, which is used in large quantities; $1 \mathrm{~kg}$ of Parmesan cheese needs 14 liters of milk.

Whey disposal is considered in the Parmesan cheese production, because whey is a co-product. It is sent to Germany and Austria by a refrigerated transport and the distance is an average between the two destination.

In Figure 3 it is possible to notice the impacts of each process and milk has the largest contribution.

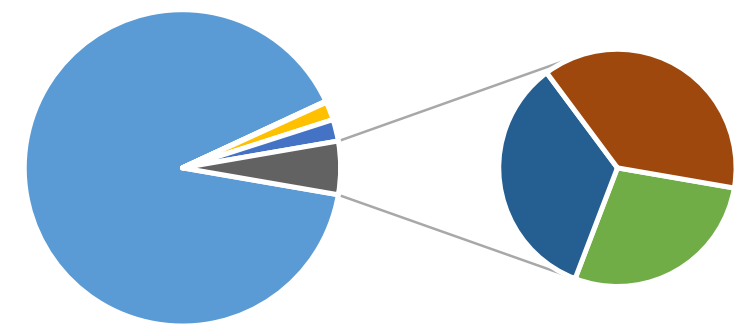

$\begin{array}{ll}\text { " Milk } & \text { " Materials } \\ \text { = Water } & \text { " Electricity } \\ \text { n Steam } & \text { " Natural gas } \\ \text { - Wastewater from whey } & \text { - Whey disposal }\end{array}$

Figure 3: Carbon footprint contributions

\subsection{Water footprint}

The method to assess water footprint is AWARE. The method must be used as a water use midpoint indicator representing the Available Water Remaining per area and it assesses the potential water deprivation.

Considering the three farms, the water consumption to produce $1 \mathrm{~kg}$ of FPCM is in a range between 0,487 and $0,673 \mathrm{~m}^{3}$.

Milking and feeding of lactating bovines are the most impactful phases; for milking process, the water is used to clean plant. Regarding the feeding, lactating cows drink daily $100 \mathrm{~kg}$ of water (it is an average data provided directly by the farmers).

As regards the water consumption to produce Parmesan cheese, the final result is $7,6 \mathrm{~m}^{3}$.

As in the previous section, in Figure 4 it is possible to identify the different contributions about consumption of water resources.

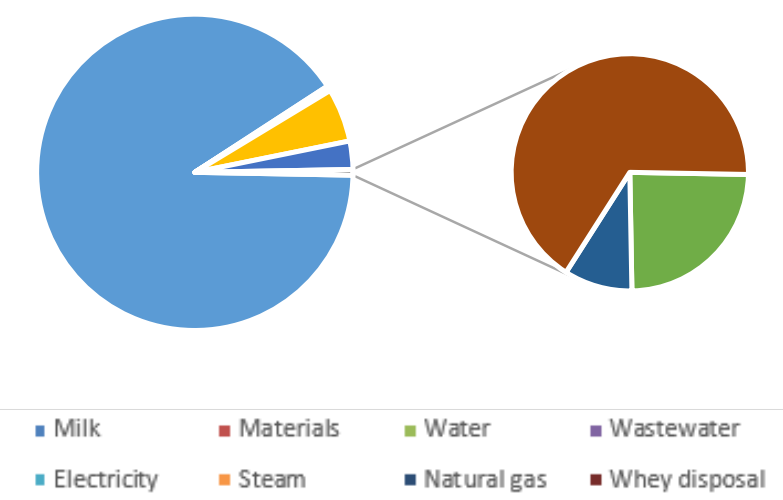

Figure 4: Water footprint contributions

As for the carbon footprint, milk is the category with the highest water consumption, due to cleaning activities and bovine water demand while dairy farm activities have a lower impact (Noya et al., 2018).

\section{CONCLUSIONS}

The aim of this analysis is to show the impacts related to greenhouse gas emissions and water consumption of $1 \mathrm{~kg}$ of organic Parmesan cheese considering the whole dairy supply chain. The study refers to the situation before future improvement measures based on the reduction of environmental impact. Future researches will be oriented to perform another Life Cycle Assessment study to compare the new situation with the previous one.

\section{ACKNOWLEDGMENTS}

This work was fouded by the research project entitled "Analisi di impatto ambientale e studio packaging innovativo per progetto OltreBio - Filiera etica del Parmigiano Reggiano biologico" which is supported by the "Piano OltreBIO - Filiera etica del Parmigiano Reggiano biologico” - PSR 2014-2020 - Tipo di operazione 16.2.01 "Supporto per progetti pilota e per lo sviluppo di nuovi prodotti, pratiche, processi e tecnologie nel settore agricolo e agroindustriale. Avviso pubblico regionale 2017 - Approccio di sistema”

\section{REFERENCES}

Bacenetti J., Bava L., Zucali M., Lovarelli D., Sandrucci A., Tamburini A., Fiala M., 2016, Anaerobic digestion and milking frequency as mitigation strategies of the environmental burden in the milk production system. Science of the Total Environment 539: 450-459

Baldini C., Bava L., Zucali M., Guarino M., 2018, Milk production Life Cycle Assessment: A comparison between estimated and measured inventory for manure 
handling. Science of the Total Environment 625 :209219.

Baldo G. L., Marino M., Rossi S., 2008, Analisi del Ciclo di Vita.

Battini F., Agostini A., Boulamanti A.K., Giuntoli J. Amaducci S., 2014, Mitigating the envirnmental impacts of milk production via anaerobiv digestion of manure: Case study of a dairy farm in the Po Valley. Science of the Total Environment 481: 196-208.

Battini F., Agostini A., Tabaglio V., Amaducci S., 2016, Environmental impacts of different dairy farming systems in the Po Valley. Journal of Cleaner Production 112: 91-102.

Bava L., Bacenetti J., Gilson G., Pellegrino L., D’Incecco P., Sandrucci A., Tamburini A., Fiala M., Zucali M., 2018, Impact assessment of traditional food manufacturing: The case of Grana Padano cheese. Science of the Total Environment 626: 1200-1209.

Bertolini M., Bottani E., Vignali G., Volpi A., 2016, Comparative life cycle assessment of packaging systems for extended shelf life milk. Packaging Technology and Science 29 (10), 525-546.

IDF (International Dairy Federation), 2015 A common carbon footprint approach for the dairy sector. In the Bulletin of the IDF No 479/2015. International Dairy Federation, Brussels, Belgium.

Jayasundara S., Worden D., Weersink A., Wright T., VanderZaag A., Gordon R., Wagner-Riddle C., 2019, Improving farm profitability also reduces the carbon footprint of milk production in intensive dairy production systems. Journal of Cleaner Production 229: 1018-1028.

Mancini M. C., Menozzi D., Donati M., Biasini B., Veneziani M., Arfini F., 2019, Producers' and Consumers' Perception of the Sustainability of Short Food Supply Chains: The Case of Parmigiano Reggiano PDO. Sustainability 11 (3): 721.

Manfredi M, Fantin V, Vignali G, Gavara R, 2015. Environmental assessment of antimicrobial coatings for packaged fresh milk. Journal of Cleaner Production 95, 291-300

Noya I., Gonzàlez-Garcìa S., Berzosa J., Baucells F., Feijoo G., Moeira M.T., 2018, Environmental and water sustainability of milk production in Northeast Spain. Science of the Total Environment 616-617:1317-1329.

Sanjuan N., Ribal J., Clemente G., Fenollosa M.L., 2011, Measuring and Improving Eco-Efficiency Using Data Envelopment Analysis: A Case Study of MahònMenorca Cheese. Journal of Industrial Ecology 15, Issues 4: 614-628.

Uctug F. G., 2019, The Environmental Life Cycle Assessment of Dairy Products. Food Engineering Reviews 11: 104-121.
UNI EN ISO 14040:2006. Environmental management Life cycle assessment - Requirements and guidelines.

UNI EN ISO 14044:2006. Environmental management Life cycle assessment - Principles and framework.

Van Middelaar C.E., Berentsen P.B.M., Dolman M.A., de Boer I.J.M, 2011, Eco-efficiency in the production chain of Dutch semi-hard cheese. Livestock Science 139, Issues 1-2: 91-99.

\section{AUTHORS BIOGRAPHY}

Giulia BORGHESI is a scholarship holder at CIPACK research packaging centre at the University of Parma. In March 2019, she achieved a master degree in Engineering for Plants and Machines of Food Industry at the same university. Her main fields of research concern Life Cycle Assessment of food and packaging.

Giuseppe VIGNALI is an Associate Professor at University of Parma. He graduated in 2004 in Mechanical Engineering at the University of Parma. In 2009, he received his PhD in Industrial Engineering at the same university, related to the analysis and optimization of food processes. His research activities concern food processing and packaging issues and safety/security of industrial plant. Results of his studies related to the above topics have been published in more than 100 scientific papers, some of which appear in national and international journals and conferences. 


\section{Author's index}

Aquaro

Borghesi 24

Bottani 9

Cangialosi 1

Caroti 1

Cepolina 1

Coloretti 16

Di Donato 9

Ferraro 9

Giusti 1

Guareschi 9

Longo 9

Piemonte 1

Stefanini 16

Tebaldi 9

Vignali 9 